\title{
Fault Source Modeling of the 2008 Wenchuan Earthquake Based on ALOS/PALSAR Data
}

\author{
by M. Furuya, T. Kobayashi, ${ }^{*}$ Y. Takada, ${ }^{\dagger}$ and M. Murakami
}

\begin{abstract}
We use crustal deformation data sets derived from satellite-based synthetic aperture radar (SAR) to develop a fault source model of the 2008 $M_{\mathrm{w}}$ 7.9 Wenchuan earthquake, China, that occurred at the Longmen Shan fault zone. The data sets include interferometric SAR (InSAR), range offset, and azimuth offset data acquired at seven ascending paths. The range and azimuth offset data are particularly important, exhibiting a single major rupture to the northeast (NE) and multiple ruptures to the southwest (SW). Our preferred model consists of six segments; four follow the previously mapped traces of the Beichuan fault (BF) and its NE extension, one corresponds to the Pengguan fault (PF) to the SW, and the other is included to represent a conjugate fault to the SW. Fixing the location and geometry of those segments, we solve the variable slip distribution whose patch size increases toward the greater depth; we use a nonnegative least-squares method with a smoothing constraint on the distributed slip. The geodetically estimated moment is $1.05 \times 10^{21} \mathrm{Nm}$ $\left(M_{\mathrm{w}}=7.9\right)$, which is close to the seismological estimate and suggests that there are insignificant postseismic signals in the data. Maximum slip of $\sim 10 \mathrm{~m}$, consisting of both thrust and right-lateral slip components, is identified at the shallowest patches to the NE along the BF. The multiple fault segments to the SW show that the thrust slip component initially dominates, and the strike slip becomes significant toward the NE. Examining the sensitivity of the predicted azimuth offset data to the assumed dip angle, we found that the dip angle changed significantly from $35^{\circ}-45^{\circ}$ at the $\mathrm{SW}$ fault segment for the $\mathrm{PF}$ to $80^{\circ}-90^{\circ}$ at the NE extension of the BF.
\end{abstract}

\section{Introduction}

On 12 May 2008, an earthquake with a moment magnitude of 7.9 struck near Wenchuan city, Sichuan Province, China. The earthquake caused devastating damages to nearby cities and towns, with estimated casualties of nearly 90,000 . The epicentral areas are located on the eastern edge of the Tibetan Plateau, where the Longmen Shan fault zone (LSFZ) runs over a length and width of $500 \mathrm{~km}$ and $50 \mathrm{~km}$, respectively along a northeast (NE)-southwest (SW) strike (Fig. 1; Burchfiel et al., 1995; Densmore et al., 2007; Burchfiel et al., 2008). The elevation in the LSFZ is roughly 4000 meters or more but flattens abruptly in the Sichuan basin to the southeast with an elevation on the order of $\sim 500$ meters. Nevertheless, even the largest earthquake in historical records in Wenchuan is the magnitude 6.5 event in 1657 (Huang et al., 2008), and there is only sparse geological evidence for Quaternary thrust faulting (Burchfiel et al., 1995; Densmore et al., 2007). Moreover, recent Global

\footnotetext{
*Now at Geospatial Information Authority of Japan, Tsukuba, Japan.

Now at The Disaster Prevention Research Institute, Kyoto University, Kyoto, Japan.
}

Positioning System (GPS)-based geodetic measurements prior to the earthquake indicated small horizontal crustal deformation by as much as $2-3 \mathrm{~mm} /$ year in a Tibetan Plateau fixed reference frame (Gan et al., 2007). Thus, it remains uncertain and is debated why such steep changes in topography have been formed and maintained (e.g., Burchfiel et al., 2008; Hubbard and Shaw, 2009). The 2008 Wenchuan earthquake presumably represents an ongoing eastward extrusion process of the Tibetan plateau, and thus provides us with a rare opportunity to better understand the kinematics of the major faults along the margin of the plateau.

The overall locations, geometry, and slip distribution of the fault source model were promptly inferred from the conventional waveform inversion technique, using far-field seismic observation data (e.g., Hikima, 2008; Ji, 2008; Nishimura and Yagi, 2008). All those far-field seismological studies, however, assumed a single rectangular fault plane because of limited observational data at that moment. In this study, we use crustal deformation data acquired by the L-band synthetic aperture radar (SAR) sensor, PALSAR, on 


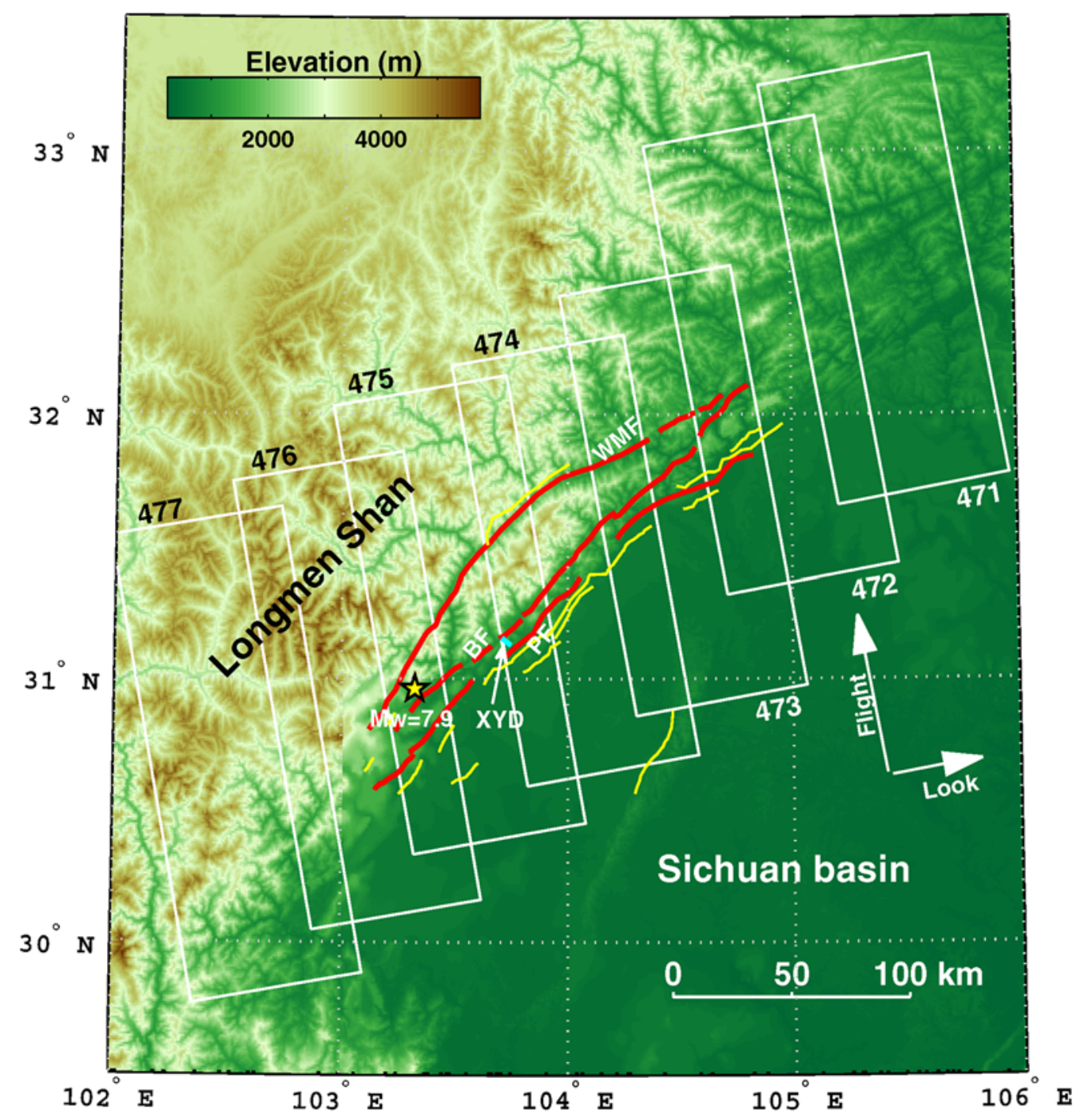

Figure 1. Location map of the Longmen Shan fault zone and regional topography. The epicenter of the Wenchuan earthquake $\left(M_{\mathrm{w}} 7.9\right)$, indicated by a star, was determined by the National Earthquake Information Center (2008). Major (thick) and minor (thin) fault traces are drawn from Densmore et al. (2007). WMF, Wenchuan-Maowen fault; BF, Beichuan fault (also referred to as the Yingxu-Beichuan fault); PF, Pengguan fault (a combination of the Xiangshui fault in the north and the An Xian-Guan Xian fault in the south); XYD, Xiaoyudong rupture zone identified by Xu et al. (2009) and Liu-Zeng et al. (2009). Seven rectangles represent the areas observed by ALOS/PALSAR; each area is designated by a path number, 471-477. The color version of this figure is available only in the electronic edition.

the Advanced Land Observation Satellite (ALOS) launched by the Japan Aerospace Exploration Agency (JAXA) so that we can examine the fault sources in more detail. Although the strengths of SAR data for geodetic studies are now widely known (e.g., Bürgmann et al., 2000), PALSAR is advantageous over other SAR sensors because its longer wavelength gives rise to a good interferometric coherence even over vegetated land surfaces (e.g., Shimada et al., 2008). Besides the standard interferometric SAR (InSAR) data, we also use pixel-offset data that are hardly affected by coherence loss and thus are indicate quantitative ground displacement data even over the epicentral areas (e.g., Michel et al., 1999; Tobita et al., 2001; Fialko et al., 2001; Kobayashi et al., 2009).

The objective of this paper is to quantify surface deformation due to the 2008 Wenchuan earthquake and to develop a fault source model, based on the dislocation Green's function in a homogeneous elastic half-space by Okada (1992). Although Kobayashi et al. (2009) and Hao et al. (2009) reported the location of ruptures and a preliminary fault source model, we refine the observational data and also revise the preliminary fault source model, using not only range-offset data but also azimuth-offset and standard InSAR data. We found that the azimuth-offset data allow us to better constrain along-strike changes in the fault dip angle from the southwestern hypocentral area to the northeastern end during the entire rupture process.

\section{Data Processing and Observation Results}

We use PALSAR data on the ascending orbital paths from 471 to 477 (Fig. 1), all of which are acquired in a 
strip-map mode with an incidence angle of $38.7^{\circ}$; see Shimada et al. (2008) for technical details on the PALSAR. Because we do not use descending track data, our InSAR and pixel-offset data can constrain only two of the full threedimensional (3D) displacements. However, because the main fault ruptures have reached to the surface, the strike direction is visibly evident. Thus even two of the $3 \mathrm{D}$ displacement components can pretty well constrain the fault sources. Because the pixel-offset data are insensitive to smaller displacements and thus inaccurate, we do not use pixel-offset data from path 477. The azimuth-offset data path 476 is not used either because it obviously revealed nontectonic but probably ionospheric effects; see the subsequent discussion. Although the PALSAR data are the same as those in our previous study (Kobayashi et al., 2009), we revise the crustal deformation data using the digital elevation model (DEM) of the National Aeronautics and Space Administration's (NASA) Shuttle Radar Topography Mission (SRTM4), in which data gaps in the original SRTM DEM are filled (Jarvis et al., 2008). We use precision orbit data provided by JAXA. No orbit reestimation is performed at any paths. No corrections for troposphere or ionosphere are applied to any paths except for path 472, in which we take out the longwavelength trend, fitting second-order polynomials.

It is impractical for the fault source modeling to use the entire sets of InSAR and pixel-offset data, primarily because there are tens of millions of points in each path. We reduce the number of data points using a quad-tree decomposition technique (e.g., Jónsson et al., 2002; Simons et al., 2002; Lohman and Simons, 2005) so that we can effectively keep only significant signals. After reduction of the InSAR and pixel-offset data, there are 6969 points for InSAR, 2847 points for range offset, and 842 points for azimuth offset; there are 10,658 data points in total.

InSAR data have better sensitivity to ground displacements with the precision on the order of $2-3 \mathrm{~cm}$ in a nonstacked image, while the precision of pixel-offset data are on the order of $15 \mathrm{~cm}$ or worse (Fialko et al., 2001; Kobayashi et al., 2009). However, interferometric coherence is almost completely lost near the fault traces partly because the spatial gradient of the ground displacements is extremely large, as observed in the pixel-offset data and partly because the surface is highly damaged and disrupted. Thus, we do not have InSAR data near the surface rupture areas (Fig. 2). In addition, low-coherence areas run across the entire range in the middle of paths 473, 474, and 475, preventing us from unwrapping the original phases across those areas. With regard to this earthquake, it is apparent that large phase jumps exist in the observed data across the fault trace due to the associated coseismic deformation. No phase unwrapping techniques, however, tell us the true phase jumps across the fault trace. In this study, we employ a minimum cost flow (MCF)

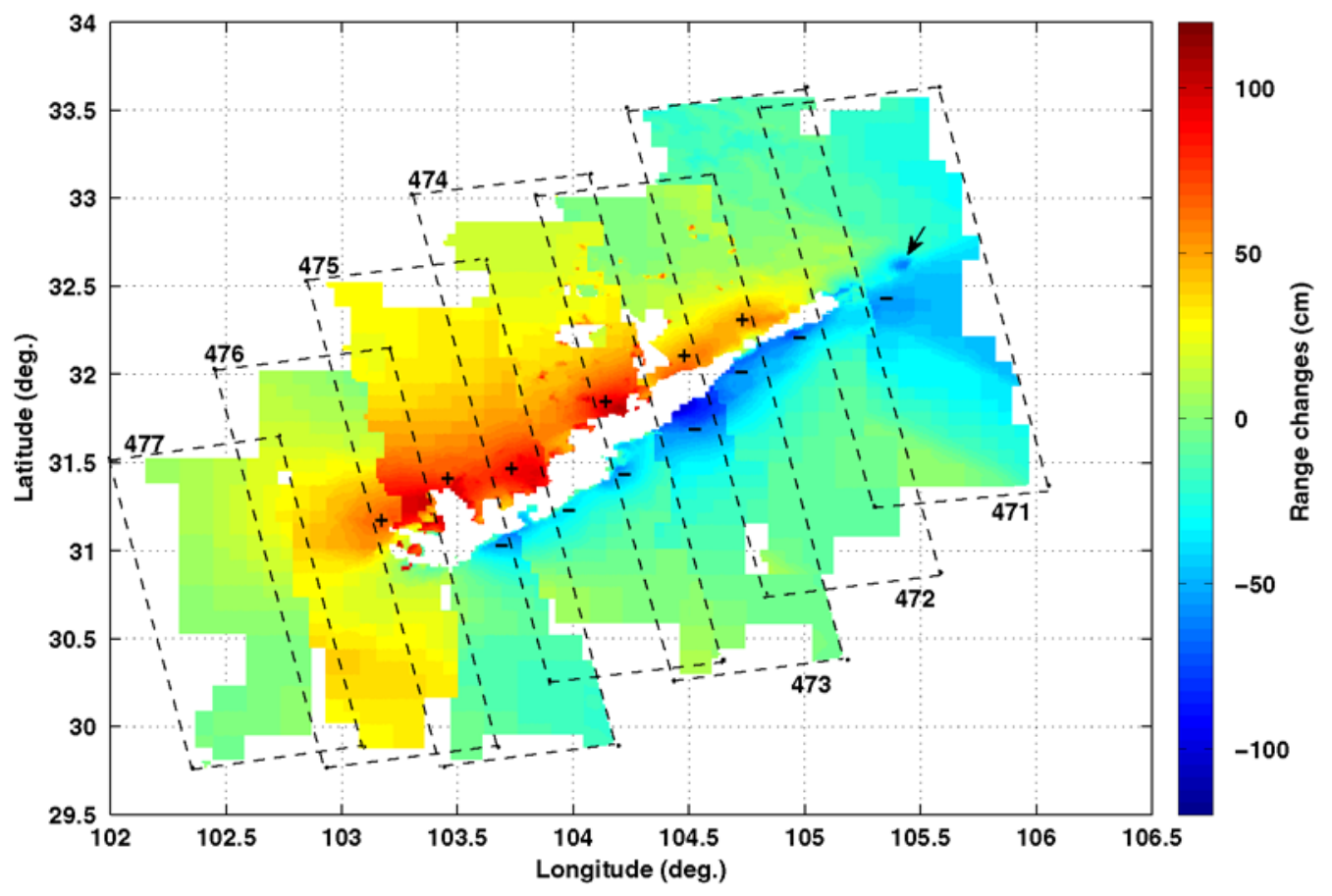

Figure 2. Observed interferograms after corrections of either the estimated jumps across the fault from paths 473,474 , and 475 or the overall offsets from paths 471, 472, and 476 (Table 1); each path is denoted by the rectangles with dashed lines. Positive (negative) values show the range changes along the radar line-of-sight away from (toward) the satellite. The range change at these paths is a linear combination of 3D displacement components and equal to $+0.616 U_{e}+0.109 U_{n}-0.780 U_{z} ; U_{e}, U_{n}$, and $U_{z}$ are taken as the positive eastward, northward, and downward components, respectively. The spotty signal denoted by an arrow from path 471 is close to the epicenter of the largest aftershock ( $M$ 6.4), but the details of the origin remain uncertain and beyond the scope of this paper. The color version of this figure is available only in the electronic edition. 
unwrapping algorithm (Costantini, 1998), assuming one phase reference point at the edge of each path; phase unwrapping was performed in the multilooked interferograms, whose number of looks were 12 and 36 in range and azimuth, respectively. Because the MCF technique tends to make the entire unwrapped phases as continuous as possible, the resulting unwrapped data contain no apparent phase jumps across the fault. However, combining the InSAR data with the range- and azimuth-offset data, we can estimate the phase jumps at those paths, letting them be the other unknown parameters that are estimated together with the fault slip distribution. The phase jumps are estimated in a least-squares sense as corrections for those original MCF-based unwrapped phase values and are thus simply real numbers, although the phase jumps should, in principle, be integer multiples of $2 \pi$ with respect to the equal phase pixels across the fault; see the Methods section for more discussion. Because the exact phase values of the reference points at the edges are uncertain, the phase values across the fault are also ambiguous even if they are unwrapped. Therefore, rather than constraining the phase jumps to be integer multiples of $2 \pi$, we estimate the phase jumps as real numbers so that they should be consistent with the pixel-offset data, and thus we also adjust the ambiguities at the reference points. Other path-following unwrapping algorithms would have to assume at least two phase reference points, one to the north and the other to the south of the fault trace, but in the presence of large tropospheric and/or ionospheric effects, it is uncertain if the assumed phase value at the reference is close to the true value.

Figure 2 shows the observed interferograms corrected for the estimated phase jumps across the fault or offsets. The estimated phase jumps are not necessarily close to the one that we visually determined (Table 1), which suggests that there are ambiguities in the original observed data, and thus we need to estimate them. Except at some places that would be strongly affected by tropospheric and/or ionospheric effects, all the interferogram fringes are continuously connected to the adjacent paths, despite the differences in the acquired dates. Although the following fault source model includes slip contributions within the earliest 1.5 months after the earthquake, this observation indicates that the coseismic deformation signals dominated over the postseismic deformation signals. Indeed, our preliminary postseis-

Table 1

Estimated Offset Values in Figure 2

\begin{tabular}{ccc}
\hline Path & Estimates $(\mathrm{cm})^{*}$ & Visually Inspected $(\mathrm{cm})$ \\
\hline 471 & -2.2 & - \\
472 & -10.6 & - \\
473 & 122.0 & 125 \\
474 & 109.9 & 95 \\
475 & 110.2 & 85 \\
476 & 17.6 & - \\
\hline
\end{tabular}

*The offset value to the north of the fault trace is shown from paths 473,474 , and 475 . mic interferograms do not show any significant signals near the fault. The ground displacements along the fault traces are uncertain in Figure 2, but the observed shape of the deformation fringe is not a single lobe and changes from the SW to the NE. Near the NE end of path 471, we can identify a spotty shortening signal (denoted by an arrow), which is likely to be a localized uplift due to a shallow thrust earthquake and is very close to the largest aftershock ( $M$ 6.4). However, the $M 6.4$ aftershock turns out to be strike slip, and the detailed origin of the spotty signal remains uncertain. We did not consider the signal in the fault source modeling.

Figure 3a,b shows the pixel-offset data for the range and azimuth components, respectively; we hereafter denote these as the range offset and azimuth offset, respectively. The search window size is $64 \times 192$ pixels (range $\times$ azimuth, $\sim 480 \mathrm{~m} \times$ $610 \mathrm{~m}$ ), and the sampling interval is $36 \times 108$ pixels. To precisely derive pixel-offset data, elevation-dependent corrections must be applied to the image registration because of the rugged terrain. In addition, because the original azimuthoffset data in the ascending track include many streaks that are nontectonic but presumably due to the ionosphere (Gray et al., 2000; Wegmüller et al., 2006), we remove those signals, applying a band-cut filter. The technical details on these processing procedures are the same as in our previous study (Kobayashi et al., 2009).

The range offset data have the same sensitivities to 3D ground displacements as the standard InSAR data, and thus the observed spatial pattern in Figure 3a is similar to that in Figure 2. Figure $3 \mathrm{a}$ indicates, however, what could not be revealed in Figure 2. Clear sign contrasts exist in the range changes across the fault trace over a distance of $\sim 300 \mathrm{~km}$. The observed locations of the jumps in range changes clearly indicate that the Beichuan fault (Fig. 1; also referred to as the Yingxiu-Beichuan fault) ruptured in the 2008 Wenchuan earthquake and that the Wenchuan-Maowen fault (Fig. 1) was not directly involved in the earthquake. Comparing the location of the Beichuan fault by Densmore et al. (2007), however, we notice that the earthquake rupture propagated further to the NE of the Beichuan fault. Furthermore, the clear sign contrasts on the surface illustrate that the earthquake rupture propagated to the surface over most of the epicentral areas. Field-based fault locations by Xu et al. (2009) are also plotted in Figure 3a,b, which are quite consistent with our pixel-offset data.

Scrutinizing Figure 3 in more detail, we see that the earthquake rupture proceeded in a complicated fashion because the pixel-offset data to the NE exhibit significant differences from those to the SW. To the NE, there is a single discontinuity in the range- and azimuth-offset data. Hence, we basically propose a single fault plane in that area. Near the NE edge, Figure $3 a, b$ shows a marked difference in sign across the trace. Although the pixel-offset data are quantitatively less precise than the standard InSAR data, we will take advantage of the sign difference to put a tight constraint on the dip angle in the modeling described subsequently in this article. On the other hand, instead of a single discontinuity to the SW, there are at 
(a)

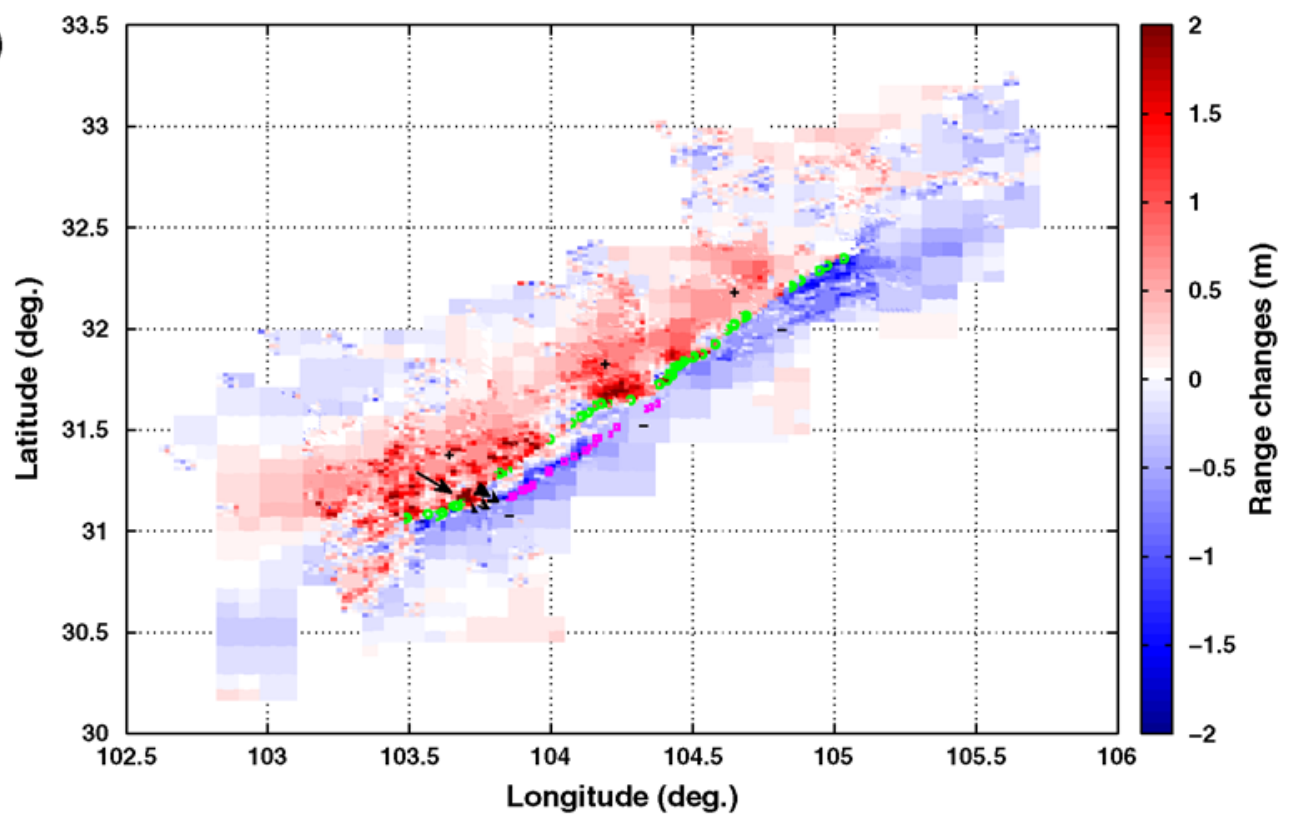

(b)

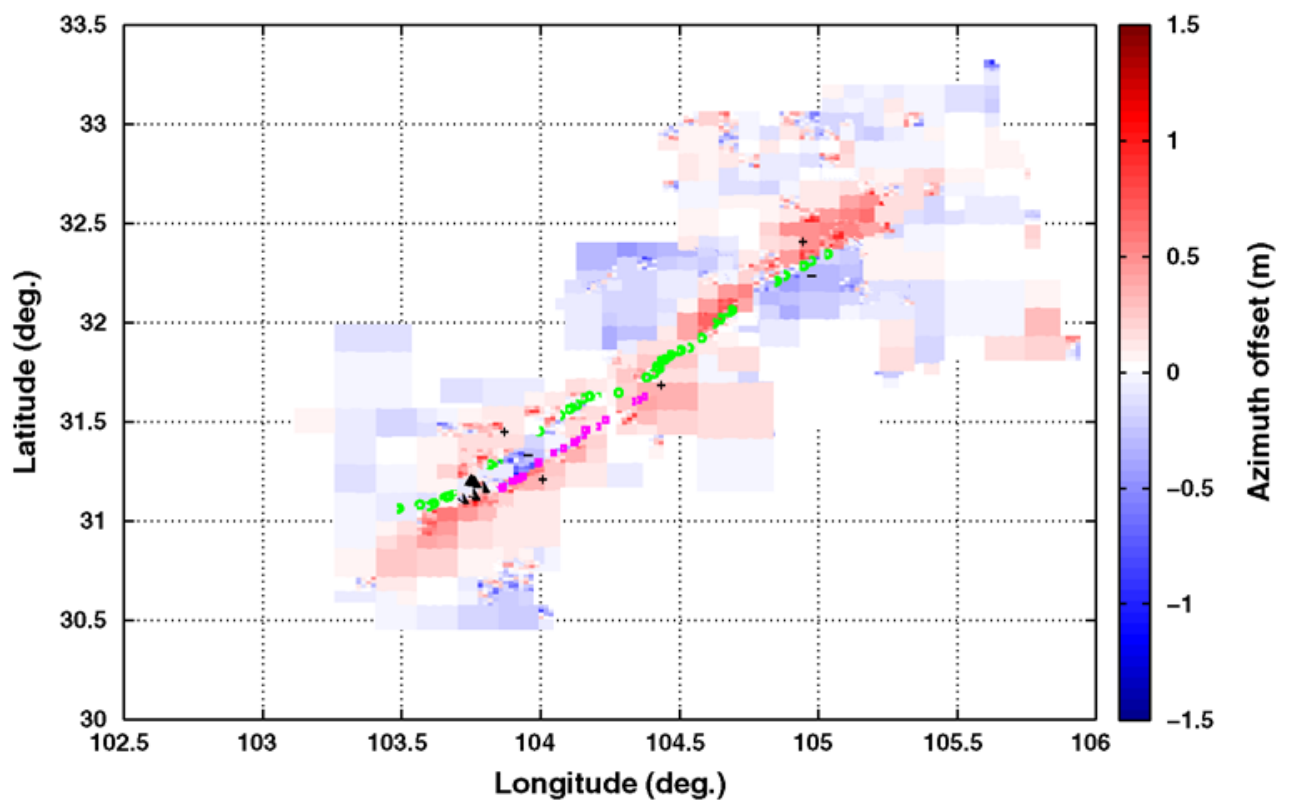

Figure 3. (a) Observed range-offset data. Positive (negative) values show the range changes along the radar line-of-sight away from (toward) the satellite, which have the same sensitivities to 3D displacements as the InSAR data. The localized signals denoted by an arrow can be associated with a conjugate fault. (b) Observed azimuth-offset data, which are a linear combination of 3D displacement components and equal to $-0.174 U_{e}+0.985 U_{n}$; note that the azimuth offset is independent from the up-down component. Markers represent field-based rupture locations identified by Xu et al. (2009); circle, square, and triangle ones are located at Yingxu-Beichuan, Hanwang, and Xiaoyudong rupture zones, respectively. The color version of this figure is available only in the electronic edition.

least two traces of significant changes in both the range offset (Fig. 3a) and azimuth offset (Fig. 3b), suggesting multiple fault traces on the surface; this is consistent with recent field observation results (Hao et al., 2009; Liu-Zeng et al., 2009; Xu et al., 2009). The two distinct traces to the SW presumably correspond to the Beichuan fault to the west and the Pengguan fault to the east, respectively (Fig. 1); the Pengguan fault is a combination of the Xiangshui fault in the north and the An Xian-Guan Xian fault in the south (Densmore et al.,
2007). Both faults are considered in our fault source modeling.

In view of Figure 3a, near the epicenter of the main shock to the SW, strongly localized positive signals (denoted by an arrow) appear that apparently cut across the major faults. The location exactly matches the Xiaoyudong rupture zone (Fig. 1), whose strike direction was identified to be perpendicular to the major faults by field surveys (Liu-Zeng et al., 2009; Xu et al., 2009). A conjugate fault plane was 
also suggested from the relocated aftershock distribution (Huang et al., 2008). At least eight aftershocks with $M>5.0$ occurred around the area (Huang et al., 2008), and we also consider this seemingly cross-cutting fault plane.

\section{Modeling}

\section{Methods}

We develop a fault source model that can reasonably account for the observed InSAR and pixel-offset data, assuming that the ground displacements are caused by distributed slip on multiple rectangular fault planes in a homogeneous elastic half-space. Using Okada's analytical solutions for the ground displacements due to dislocation sources (Okada, 1992), we infer the location, size (length and width), dip angle, strike, and slip distribution of the model faults. As already noted, the detected ground displacements from SAR data show marked differences from the NE to the SW and are complicated enough to prevent us from simply assigning a single fault plane. The number of fault segments is therefore another unknown parameter. Revising our preliminary three-segment model (Kobayashi et al., 2009), we set six fault segments in this study (F1-F6 in Fig. 4) because the azimuthoffset data require more complicated fault segments. Three northeastern segments, F1, F2, and F3, are mainly set to account for the signals to the NE, while F4 and F5 are the two fault segments to the SW. F6 is introduced to represent the cross-cutting fault source near Xiaoyudong. We recognize that the F6 intersects with F4 and F5 in Figure 4, which is mechanically incompatible. Based on the field survey results (Liu-Zeng et al., 2009; Xu et al., 2009), however, the Xiaoyudong rupture zones link the two major ruptures at the southern edge of the Pengguan fault. It is likely that the actual F4 and F5 would consist of shorter segments that have a transfer fault between them at this location. The fault configurations in
Figure 4 could thus be viewed as a simplification of the actual more complex segments.

To invert simultaneously for all those fault parameters is a highly nonlinear and computationally formidable problem because the numbers of both data points and unknown model parameters are extremely large. Regarding the geometric parameters, however, the pixel-offset data (Fig. 3) allow us to readily locate the top of the fault, telling us visually the location, length, and strike. In practice, because they are not accurate enough to give smaller misfits, we set realistic bounds around those visually inspected values and perform a forward grid search. Moreover, because we now know that each fault plane reaches the surface, two of the three parameters (width, bottom depth, and dip angle) can uniquely determine the third. Here we assume that the bottom depth is in a range between 20 and $25 \mathrm{~km}$ and give a realistic bound to the dip angle with an increment of $5^{\circ}$. We examine a variety of relative configurations of F4 and F5 but constrain that the F4 and F5 do not intersect with each other. Our approach to derive optimum parameters is basically a forward grid search (e.g., Simons et al., 2002). Once we fix the location, size, dip, and strike of the model faults, we can compute the dislocation Green's function at each slip patch on the model fault plane(s). Then, the slip amount at each patch is the only unknown parameter, and the inversion problem becomes linear and more tractable (e.g., Jónsson et al., 2002; Simons et al., 2002; Wright et al., 2003; Fialko, 2004). At each step of the grid search for possible geometric parameters, we recalculate the Green's function for each slip patch and derive distributed slip solution and misfit residuals.

There are six fault planes, five of which need their dip angle and depth to be resolved by grid search. Strictly, the grid search should be done in the 10-dimensional (dip angle and depth of five faults) parameter space in order to account for trade-offs between parameters of different faults.

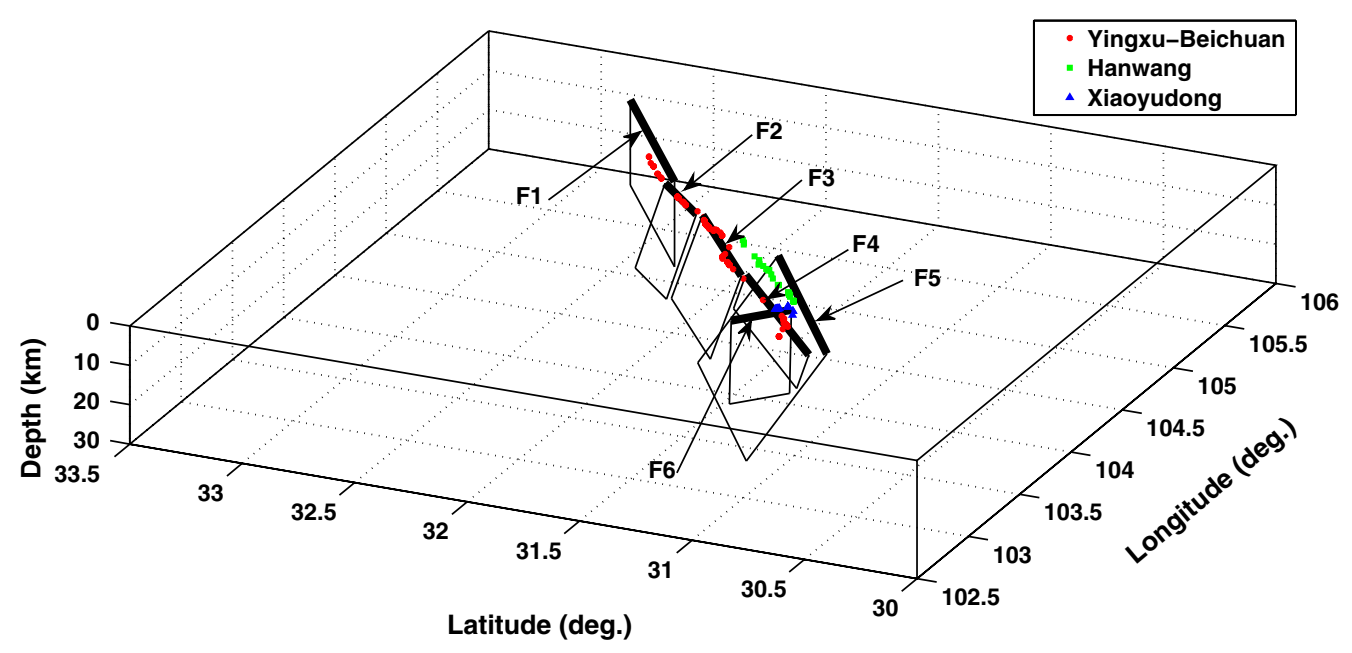

Figure 4. Three-dimensional geometry of the six fault segments of our preferred fault source model. Thick lines denote the top of each segment. See Table 2 for details. Markers represent field-based rupture locations identified by Xu et al. (2009); diamond, square, and triangle ones are located at the Yingxu-Beichuan, Hanwang, and Xiaoyudong rupture zones, respectively. The color version of this figure is available only in the electronic edition. 
However, the fault parameters at distant locations will not significantly affect any localized crustal deformation signals that are theoretically most sensitive to the parameters at shallow depths. Thus, considering the parameter correlations with neighbor faults, we carry out the grid search in fourdimensional parameter space for the F1 and F5(F4) at the $\mathrm{NE}$ and SW edges and six-dimensional parameter space for the F2 and F3 in the middle.

We consider all the observational data as independent, and the error covariance matrix is diagonal with uncertainties of $3 \mathrm{~cm}$ for the InSAR and $25 \mathrm{~cm}$ for the pixel-offset data. The weighted observation vector $\mathbf{d}$ becomes

$$
\mathbf{d}=\left(\begin{array}{c}
d_{\mathrm{InSAR}} / 3 \\
d_{\text {range }} / 25 \\
d_{\text {azimuth }} / 25
\end{array}\right)
$$

To avoid unrealistic estimates of the fault slip, we apply a smoothness constraint by minimizing the spatial second derivatives of the slip vector. As mentioned before, we set offset values in the InSAR data as unknown parameters. From paths 473 to 475 , the offset value to the north of the fault is estimated, whereas from paths 471,472 , and 476 the offset value for the entire scene is estimated (Table 1); we interpret that the offset values paths 471, 472, and 476 are caused by troposphere and/or ionosphere. Thus, we solve the following linear system of coupled equations:

$$
\left(\begin{array}{c}
\mathbf{d} \\
\mathbf{0}
\end{array}\right)=\left(\begin{array}{c}
\mathbf{G} \\
\kappa^{2} \mathbf{D}
\end{array}\right) \mathbf{m}+\left(\begin{array}{c}
\mathbf{I}_{o} \\
\mathbf{0}
\end{array}\right) \mathbf{m}_{o},
$$

which is transformed into the following equation:

$$
\mathbf{G}^{\prime} \cdot \mathbf{d}=\left(\left(\mathbf{G}^{\prime} \cdot \mathbf{G}+\kappa^{2} \mathbf{D}^{\prime} \cdot \mathbf{D}\right) \mathbf{G}^{\prime} \cdot \mathbf{I}_{o}\right)\left(\begin{array}{c}
\mathbf{m} \\
\mathbf{m}_{o}
\end{array}\right)
$$

Here, $\mathbf{m}$ is the vector of slip parameters at each patch of the fault segments, and $\mathbf{m}_{o}$ is the vector of the offset values in the InSAR data at the prescribed path. The matrix $\mathbf{G}$ is the Green's function relating the surface displacement data to the fault source parameters, weighted by the assumed uncertainties, and the prime mark stands for transposed matrices. The number of columns in the matrix $\mathbf{I}_{o}$ is now six, which is equal to the number of paths where the jumps/offsets are estimated, and nonzero elements of matrix $\mathbf{I}_{o}$ prescribe where the offset values in InSAR data are estimated; the number of rows in the $\mathbf{I}_{o}$ is now 6969. The matrix $\mathbf{D}$ is a second-order finite difference operator. Depending on the fault segment, there are two or three zones of equal patch sizes. For the second-order smoothing, we employed equation (A1) in Jónsson et al. (2002) that explicitly includes the distances between adjacent patches, and we changed them depending on which zone the patch was located. The parameter $\kappa^{2}$ is a hyperparameter that can adjust the strength of slip smoothing. There is a trade-off between the strength of smoothing and the misfit between the observed and calcu- lated signals. Our preferred model was derived by plotting the trade-off curve and picking the $\kappa^{2}$ over which the misfit does not significantly decrease.

Moreover, in solving the linear system of equations mentioned thus far, we applied a nonnegativity constraint on the signs of fault slip in which only right-lateral and dip components are allowed for the solution (e.g., Jónsson et al. 2002; Simons et al., 2002); for F6, however, only left-lateral and dip components are allowed. Furthermore, because the resolving power of slip inversion from ground displacement data becomes worse at greater depths (e.g., Bos and Spakman, 2003), we increased the patch size from $5 \mathrm{~km}$ at the shallowest depth to $\sim 12 \mathrm{~km}$ at the deepest patch, as shown in Figure 5 (e.g., Simons et al., 2002; Fialko, 2004; Motagh et al., 2006).

\section{Results and Discussion}

Figure 4 shows the location and geometry of our preferred source model, in which we acknowledge that the optimized locations of F1 and F5 are distant from the surface rupture observations by $\mathrm{Xu}$ et al. (2009) and from pixeloffset data. However, the locations of both F1 and F5 are optimized as depicted in Figure 4, and we discuss the reasons later when we compare the observations and the predictions.

The slip distributions of each fault segment are shown in Figure 5; Table 2 shows the details of each fault segment. To estimate the uncertainties of the inferred slip distribution, we synthetically generate 100 spatially correlated noises at each path, add them to the predicted data, and again perform the same linear inversion (e.g., Furuya and Satyabala, 2008). Figure 6 shows the estimated 1-sigma uncertainties of the inferred slip distribution, from which we are convinced that the uncertainties are less than 1-2 $\mathrm{m}$ at shallower depths and that the inferred slip magnitude at greater depth is less reliable. The released moment is calculated to be $1.05 \times$ $10^{21} \mathrm{Nm}\left(M_{\mathrm{w}}=7.9\right)$, close to the seismological estimate, suggesting that there are insignificant postseismic signals in the data. Comparing our fault model with previously reported fault models from waveform inversion analyses (Hikima, 2008; Ji, 2008; Nishimura and Yagi, 2008), GPS and InSAR data (Shen et al., 2009; Tong et al., 2010), and field observations (Liu-Zeng et al., 2009; Xu et al., 2009), we notice both similarities and differences. The slip distribution consists of both thrust and right-lateral components; and, to the NE, the right-lateral components become dominant, which is largely consistent with those previous studies. In terms of the geometry of fault segments, however, our fault model consists of multiple planes to the SW and most notably indicates significant changes in the dip angle from the SW to the NE. Although the estimated dip angles in F4 and F5 are $55^{\circ}$ and $35^{\circ}$, respectively, F1 becomes vertical (Table 2). Our inferred dip angle change is quite consistent with the results by Shen et al. (2009) and Tong et al. (2010), who employed GPS and InSAR data instead of pixel-offset data in the fault modeling. We subsequently discuss that azimuth-offset data 
(a) F1

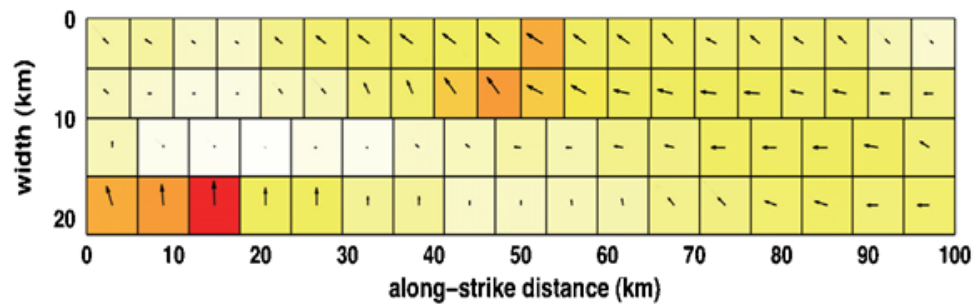

(b)

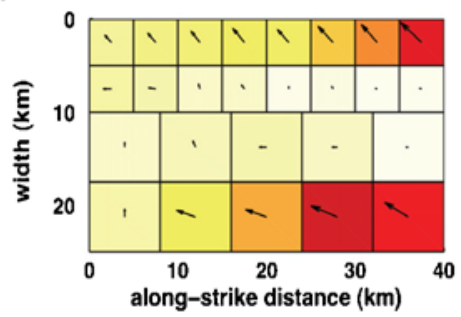

(c)

(d)

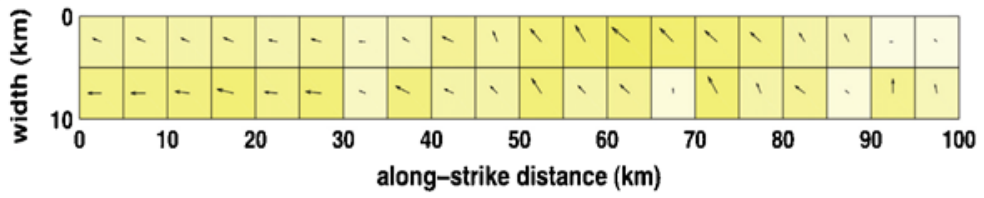

(e) F5

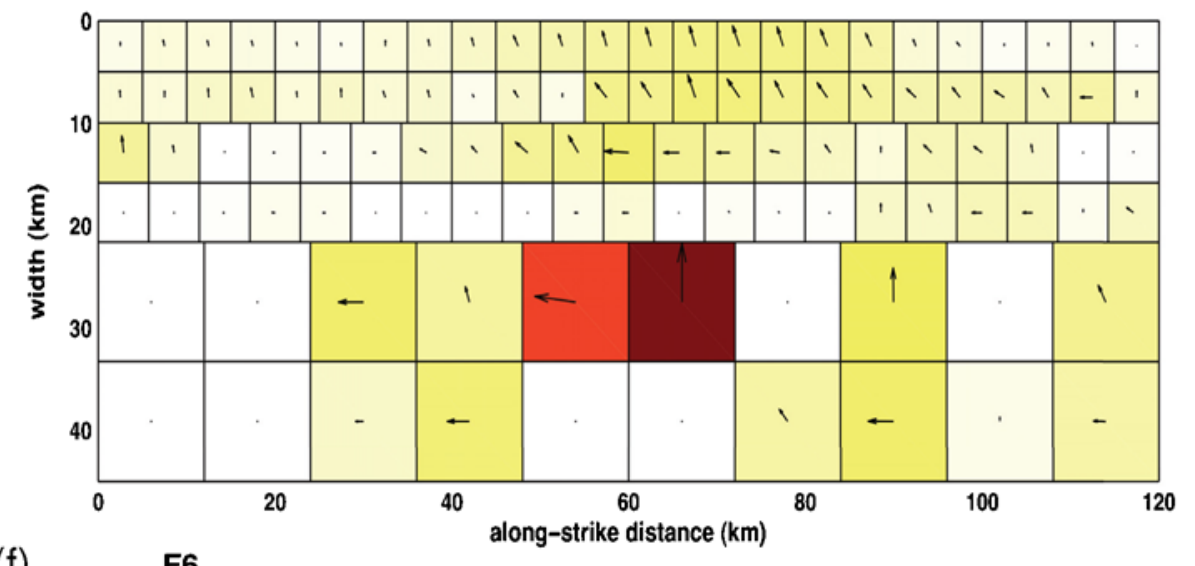

(f)

F6

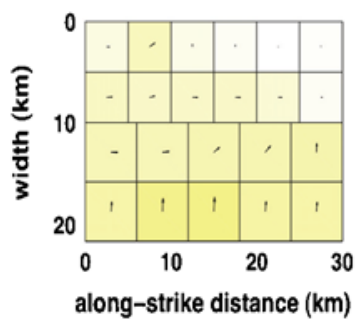

Slip magnitude $(\mathrm{m})$

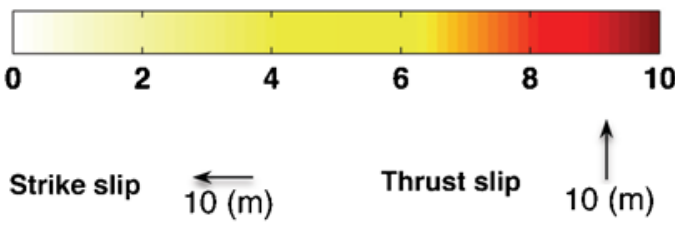

Figure 5. Slip magnitude distribution and inferred slip vectors for each fault segment. The width at each panel is the down-dip length of each fault segment. See Figure 4 for the geometry of each segment. The color version of this figure is available only in the electronic edition.

play a key role in constraining the along-strike dip angle changes. The maximally slipped patch that slips as much as $\sim 10 \mathrm{~m}$, was identified at the shallowest zone of F2-F3. This estimate is close to the result of Hao et al. (2009) and Liu-Zeng et al. (2009). Although preliminary seismological estimates (Hao et al., 2009; Shen et al., 2009) proposed another large asperity to the SW, no corresponding large slip patches appear in Figure 5; we consider that the largest slip 
Table 2

Model Parameters of the Fault Segments in Figure 4

\begin{tabular}{cccccccc}
\hline Segment & Longitude (deg.)* & Latitude (deg.)* & Bottom $(\mathrm{km})$ & Length $(\mathrm{km})$ & Width $(\mathrm{km})$ & Dip (deg.) & Strike (deg.) \\
\hline F1 & 105.56 & 32.67 & 21.67 & 100.0 & 21.67 & 90 & 234 \\
F2 & 104.71 & 32.26 & 20.48 & 40.00 & 25.00 & 55 & 232 \\
F3 & 104.47 & 31.99 & 20.48 & 75.00 & 25.00 & 55 & 232 \\
F4 & 104.00 & 31.50 & 8.2 & 100.0 & 10.00 & 55 & 229 \\
F5 & 104.09 & 31.70 & 25.81 & 120.0 & 45.00 & 35 & 235 \\
F6 & 103.78 & 31.15 & 21.58 & 30.00 & 21.67 & 85 & 310 \\
\hline
\end{tabular}

*The lower-left location of each fault segment in Figure 5 is shown.

patch in the deeper portion of F5 is less reliable (Fig. 6). However, the combination of F4 and F5 may correspond to the large apparent asperity proposed in those previous analyses. Although the estimated slip on F6 consists mostly of left-lateral strike slip components, the inferred slip amplitude is almost comparable to the estimated uncertainty. This is probably because the predicted crustal deformation by F6 contributes less significantly.

How robust are the inferred changes in the dip angle from the SW to the NE? We examined how the predicted pixel-offset data would change, depending on the prescribed dip angle. The results are shown in Figure 7 and Figure 8; other geometric parameters and the top of each fault segment are fixed and the same as those in Figure 4, but slip distribution is derived for each assumed geometry. Figure 7 shows the predicted range-offset data (a, c, e, g) and azimuth-offset data $(b, d, f, h)$ around $F 1$ to the NE, and Figure 8 shows the predicted range-offset data ( $\mathrm{a}, \mathrm{c}, \mathrm{e}, \mathrm{g})$ and azimuth-offset data (b, d, f, h) around F5 to the SW, respectively. Despite the large changes in the depicted dip angle, Figure 7 and Figure 8 do not clearly show the associated changes in the predicted range-offset data, in contrast to the azimuth-offset data, and therefore, in the case of the Wenchuan earthquake, the rangeoffset data and InSAR data are insensitive to variations in the dip angle. On the other hand, Figure 7 and Figure 8 indicate that the azimuth-offset data depend significantly on the dip angle; the misfit residual originates largely from the azimuthoffset data. This must be because the azimuth-offset data have much better sensitivity to north-south displacement than the InSAR and range-offset data even if they are derived along a single path. Although the InSAR and range-offset data are equal to $+0.616 U_{e}+0.109 U_{n}-0.780 U_{z}$, the azimuth-offset data are equal to $-0.174 U_{e}+0.985 U_{n} ; U_{e}$, $U_{n}$, and $U_{z}$ are taken as the positive eastward, northward, and downward component, respectively. Although the northsouth displacement component is difficult to infer from InSAR data (e.g., Wright et al., 2004), the azimuth-offset data are quite helpful and strongly the fault source modeling (e.g., Jónsson et al. 2002; Simons et al., 2002).

If we set a shallower dip angle for the F1 fault model, the predicted azimuth offset shows broadly positive signals (Fig. 7b,d) and never exhibits the sign changes observed in Figure 3b. The acceptable range for the dip angle in F1 would thus be $80^{\circ}-90^{\circ}$, although the predicted amplitude in the azimuth offset is significantly larger than that observed in Figure 3b. It remains uncertain, however, why the predicted amplitude in the azimuth offset data is larger than the observed one. It may be due to errors in the observed azimuth-offset data that underestimate the actual azimuth offset because of ionospheric effects and/or to the subsequent filtering procedure. Moreover, because we also observe large residuals in the range-offset data in the same areas to the NE, it is also likely that other unmodeled effects are included in the observed data.

Figure 8 shows that if a dip angle larger than $50^{\circ}$ is assumed for F5, we could not reproduce the southern one of the two traces to the SW in the azimuth offset (Fig. 3b). The acceptable range in the dip angle for $\mathrm{F} 5$ would be $35^{\circ}-45^{\circ}$. We may consider the reported centroid moment tensor (CMT) solutions as additional evidence for the shallow dip angle to the SW. The CMT solutions show shallower dip angles, ranging from $35^{\circ}$ to $39^{\circ}$ (the Global CMT Project, see Data and Resources section; Zhang et al., 2009), which is consistent with the dip angle of F5. The hypocenter is located at the southwestern edge of the model. Although more detailed seismological studies on the initial sense of fault motion are necessary, we may interpret this to mean that the earthquake rupture began at the deeper zone of F5 and branched into the steeper F4 and the shallower F5. The surface traces of the Beichuan and Pengguan faults (Fig. 1) correspond to the tops of F4 and F5, respectively.

Figure 4 and Figure 5 illustrate that the rupture style changed significantly from low-angle thrust slip to the SW toward vertical strike slip to the NE, which seems reasonable in terms of the large-scale changes in topography. Low-angle thrust slip generally leads to significant uplift at the surface of the hanging wall, while vertical strike slip drives transcurrent motion of adjacent blocks, and the subsequent uplift is less significant. To the SW, the Longmen Shan areas are characterized by abruptly steepening mountains, but the NE extension of the LSFZ becomes rather flat. The characteristic regional relief might have been generated and maintained by recurrent fault movements, such as the 2008 Wenchuan earthquake, in which the dip angle has changed significantly from the SW to the NE. The NE vertical strike-slip fault suggested in this study might merge with the eastern extension of the Kunlun fault to the north, as assumed in GPS modeling by Meade (2007). 
(a)

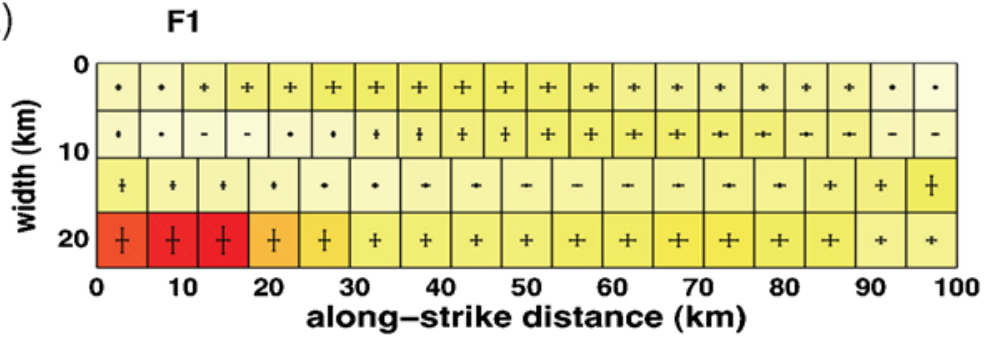

(b)

F2

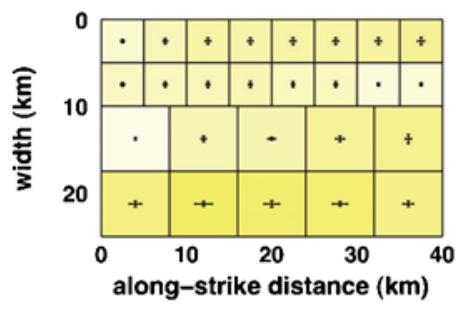

(c)

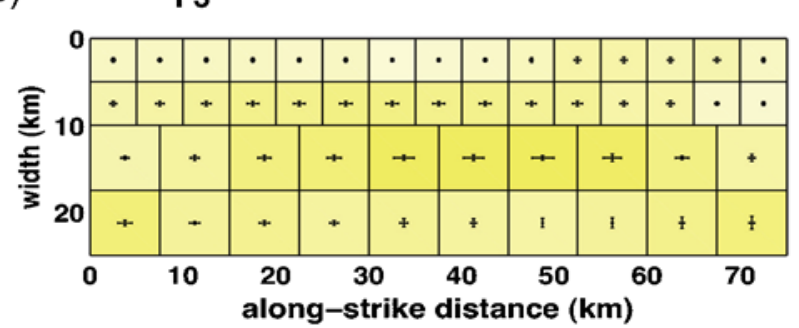

(d)

F4

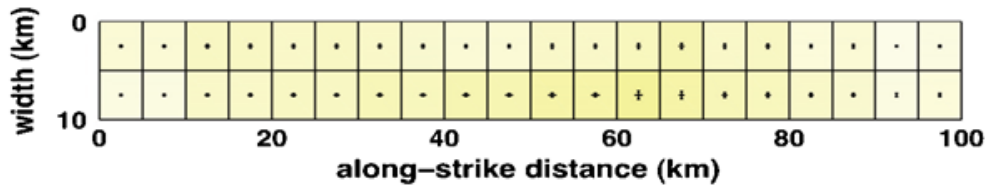

(e)

F5

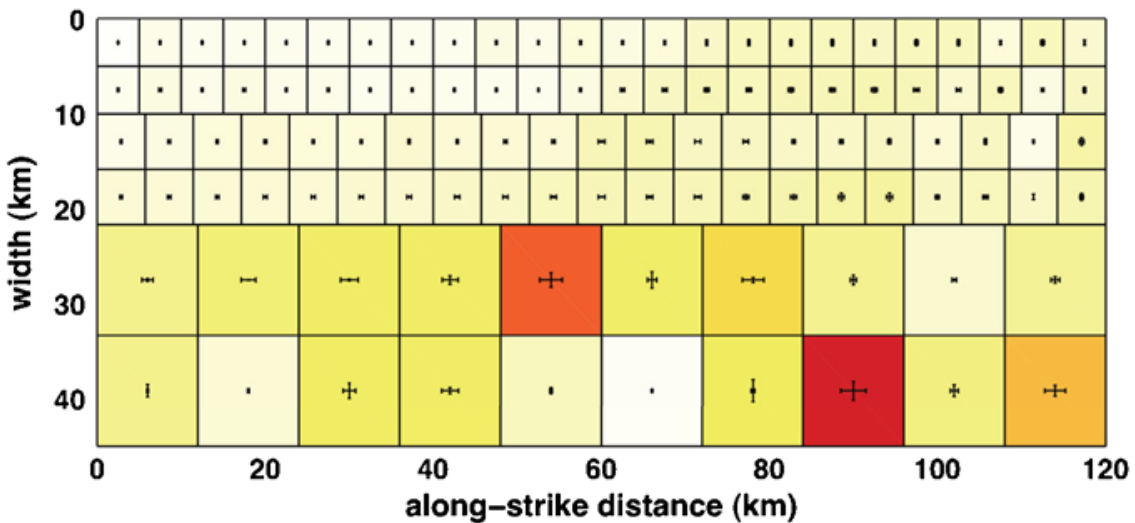

(f)

F6

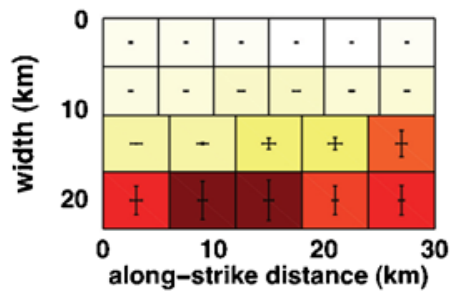

Uncertainties in slip magnitude (m)

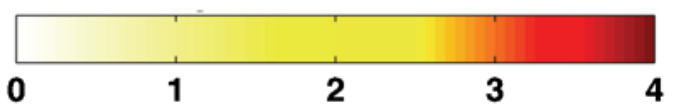

Strike slip
uncertainties $4(\mathrm{~m}) \quad \begin{aligned} & \text { Thrust slip } \\ & \text { uncertainties }\end{aligned} \quad$ I (m)

Figure 6. One-sigma uncertainties of the estimated slip distribution in Figure 5. Vertical and horizontal bars represent uncertainties for dip slip and strike slip, respectively. The patch shades stand for the magnitude of those uncertainties calculated from the square root of the sum of the squared uncertainties. The color version of this figure is available only in the electronic edition.

Figures 9-11 show (1) the predicted data and (2) their deviations from the observed InSAR, range-offset, and azimuth-offset data, respectively, all of which are based on the fault model in Figures 4 and 5. Two large-scale positive lobes in Figure 9a and Figure 10a to the north of the fault trace would be due to the changes in rupture style from the
SW to the NE. Note, however, that our source model could not explain all of the signals. In particular, significant residuals have remained from the center to the south of F3 (Fig. 9b, Fig. 10b, and Fig. 11b), although the location of F3 is almost identical to the surface rupture observations in Figure 4. Because the area seems to be in a transition zone from the 
(a)

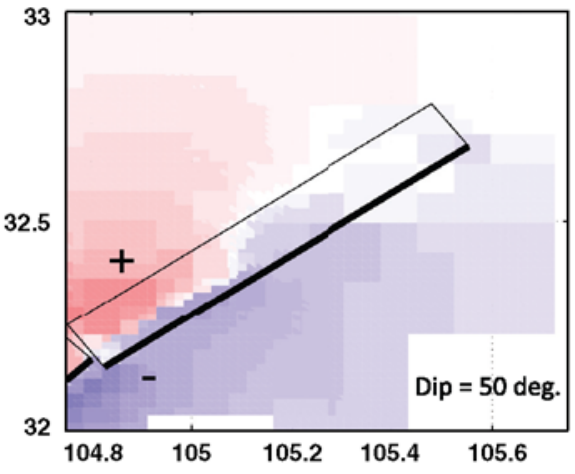

(c)

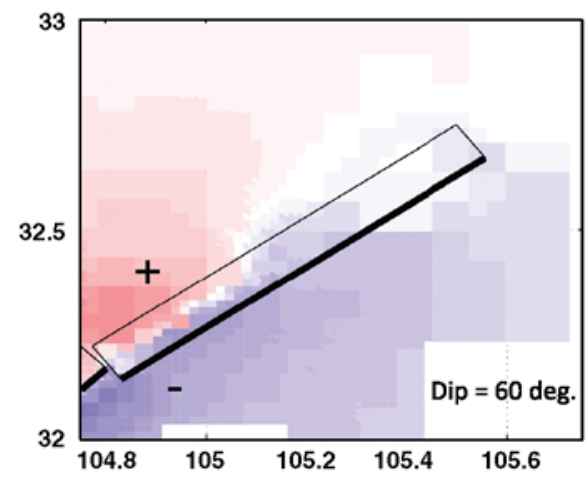

(e)

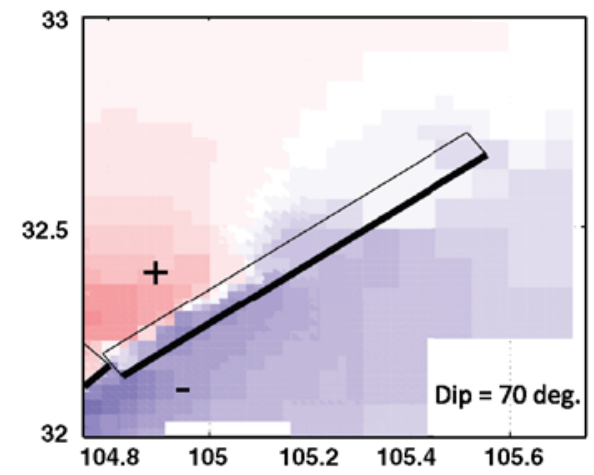

(g)

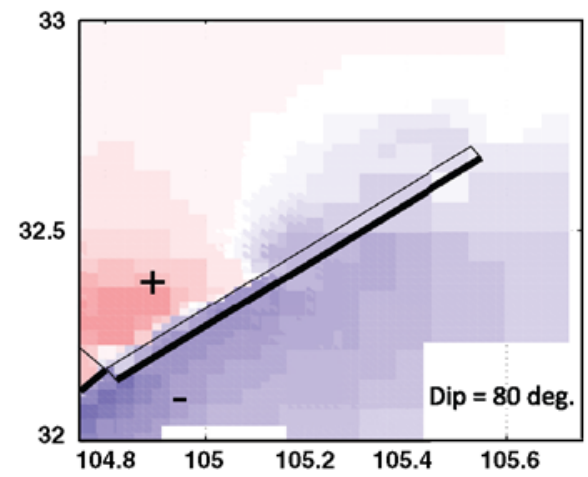

(b)

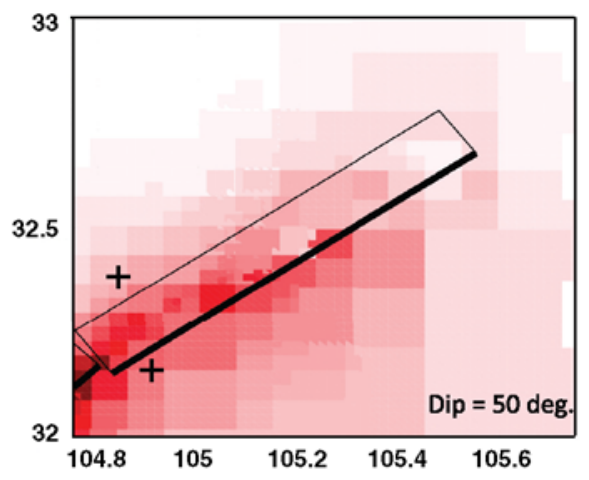

(d)

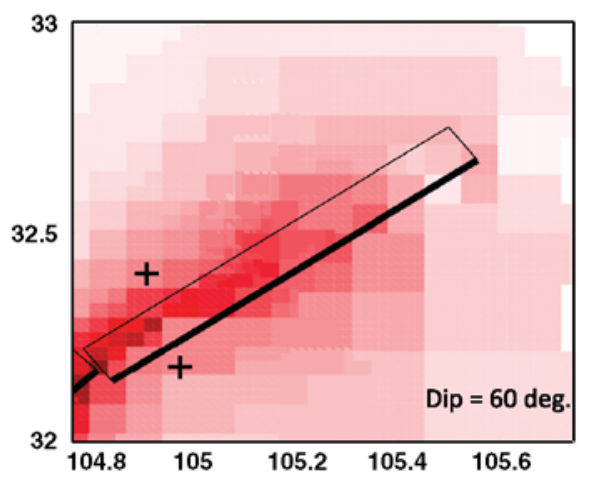

(f)

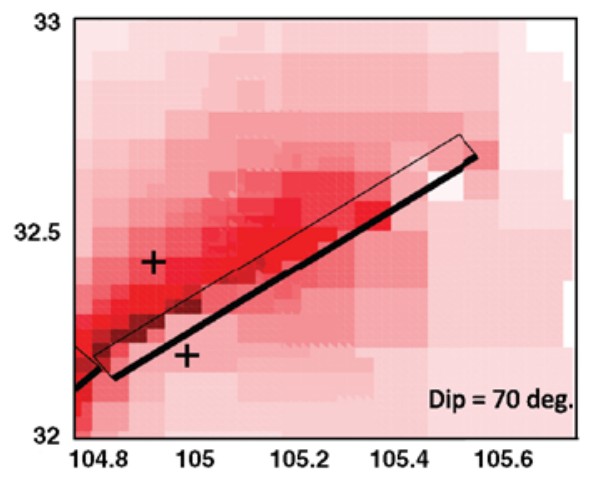

(h)

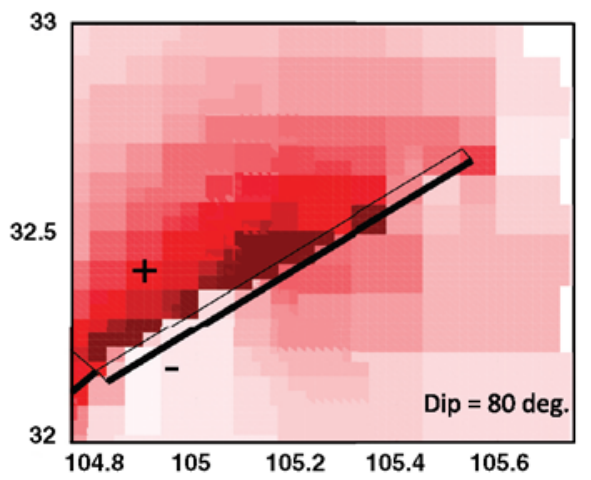

Figure 7. (a, c, e, g) Predicted range-offset data and (b, d, f, h) azimuth-offset data around fault segment F1, assuming different dip angle of F1. Plane view of the assumed F1 is also plotted, and thick lines are the top of F1. Gray scales for the range offset (a, c, e, g) and azimuth offset $(b, d, f, h)$ are the same as those in Figure $3 a$ and b, respectively. The color version of this figure is available only in the electronic edition.

SW to the NE, the actual source could be more complicated, and the geometry of segment F3 might be oversimplified. Meanwhile, according to the relocated aftershock distribution (see fig. 4 in Huang et al., 2008), no earthquakes with $M>5$ and fewer aftershocks were occurring around that very area, suggesting significant aseismic slips around the transition 

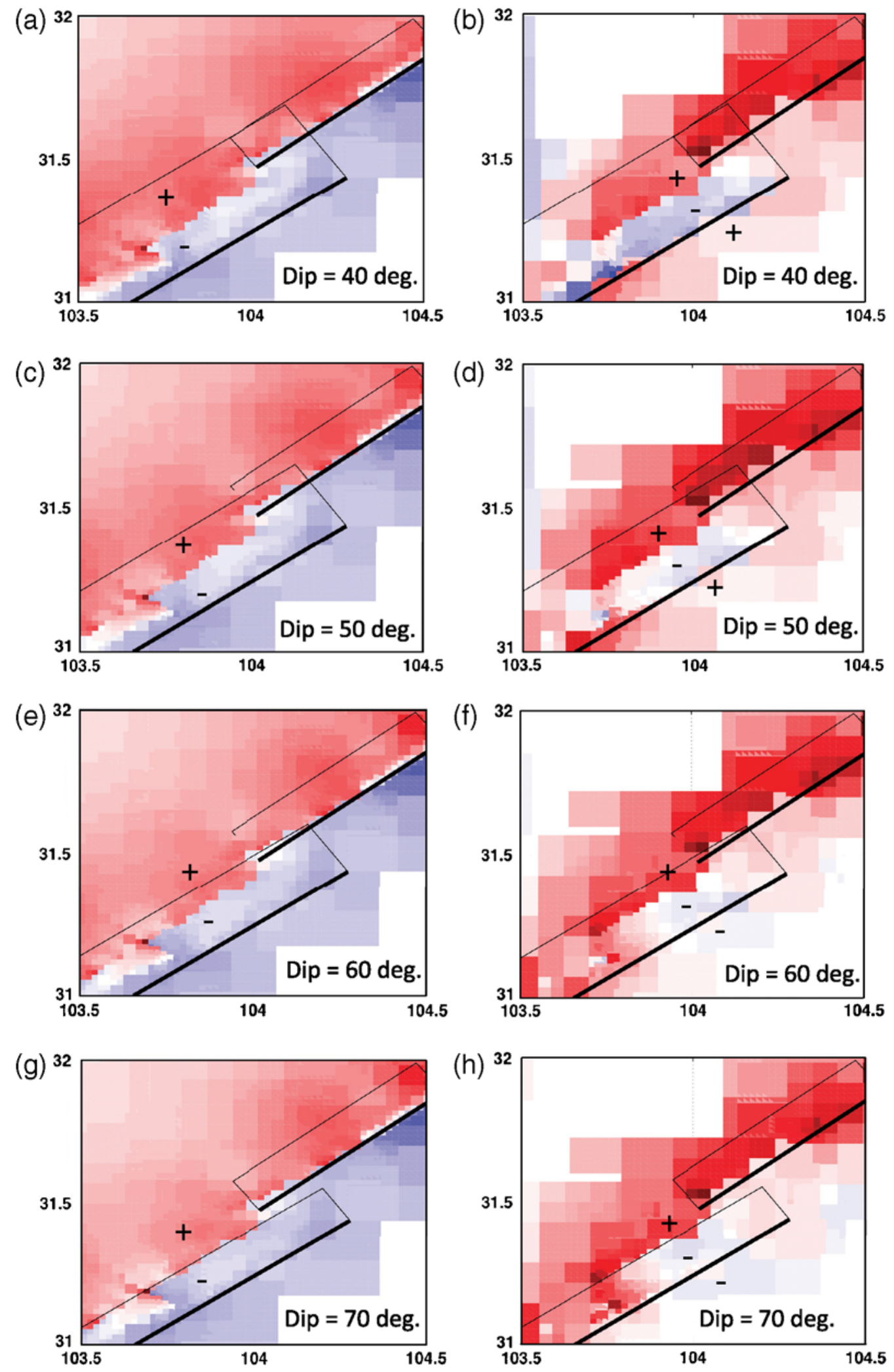

Figure 8. (a, c, e, g) Predicted range-offset data and (b, d, f, h) azimuth-offset data around fault segment F5, assuming different dip angle of F5. Plane view of the assumed F5 and F3 is also plotted, and thick lines are the top of F5 and F3; F4 and F6 are not shown for clarity. Gray scales for the range offset $(\mathrm{a}, \mathrm{c}, \mathrm{e}, \mathrm{g})$ and azimuth offset $(\mathrm{b}, \mathrm{d}, \mathrm{f}, \mathrm{h})$ are the same as those in Figure $3 \mathrm{a}$ and $\mathrm{b}$, respectively. The color version of this figure is available only in the electronic edition. 

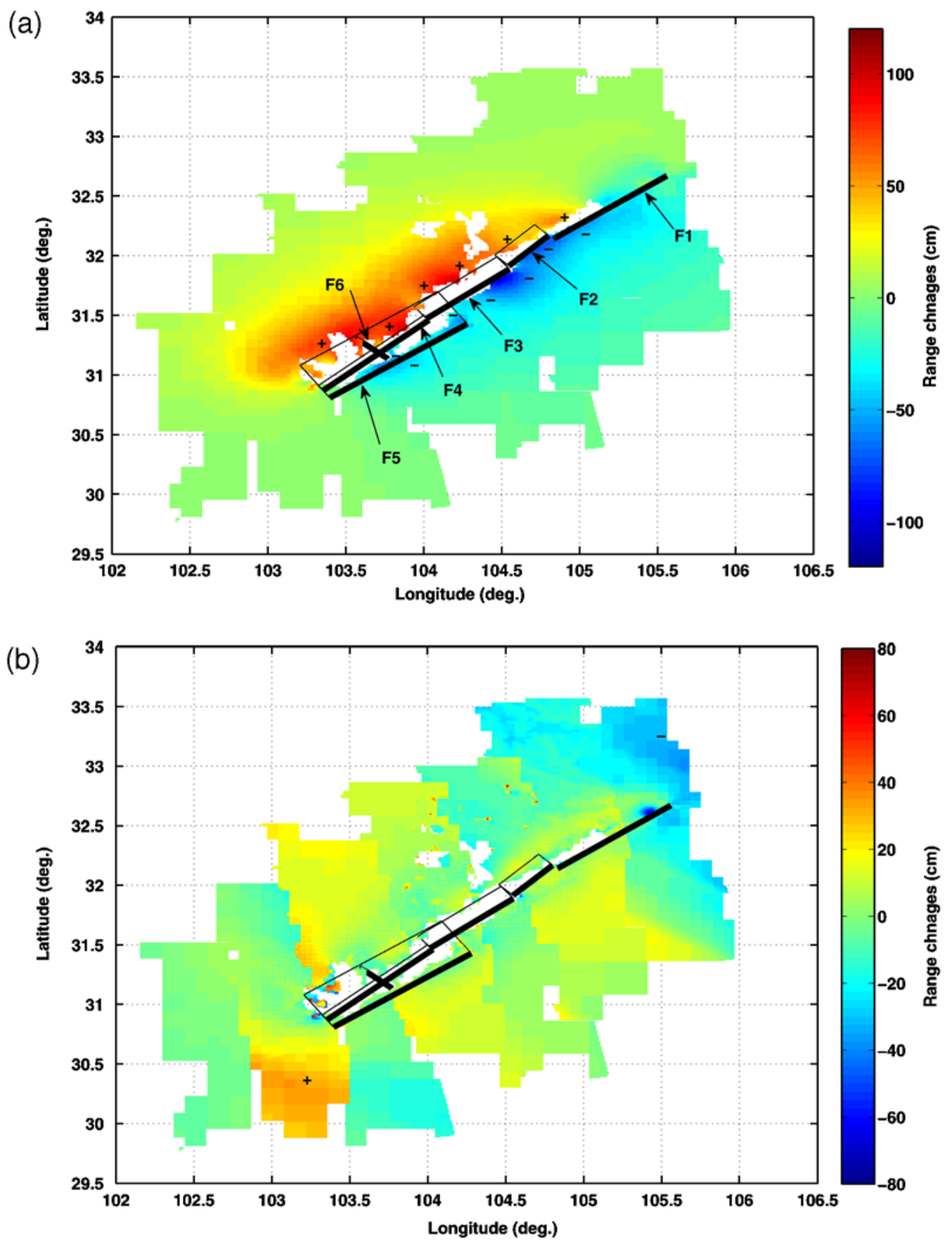

Figure 9. (a) Predicted InSAR data based on the source model in Figure 4 and Figure 5. (b) Residuals between the observed and predicted InSAR data. Plane view of the six fault segments is also shown, and thick lines are the surface traces of the segments. The color version of this figure is available only in the electronic edition.

zone. More details on rupture propagation around the transition zone remain to be elucidated.

The localized large negative signals to the NE and SW in the range offset are also unexplained (denoted by two arrows in Fig. 10b), although F1 and F5 could explain the broad features in Figure 3a,b. Actually, the locations of the unexplained signals are close to the surface rupture observations by both our pixel-offset data and Xu et al. (2009), which caused the mismatch in the locations between the fault models (F1 and F5) and the observed ruptures in Figure 4. However, if we deliberately shift the locations of F1 and F5 exactly to the observed rupture locations, the model solution becomes no longer optimum because it fails to account for the other significant signals and generates even larger misfit residuals. This apparent dilemma suggests an oversimplification of the present F1 fault model. Looking into the range-offset signals 
(a)

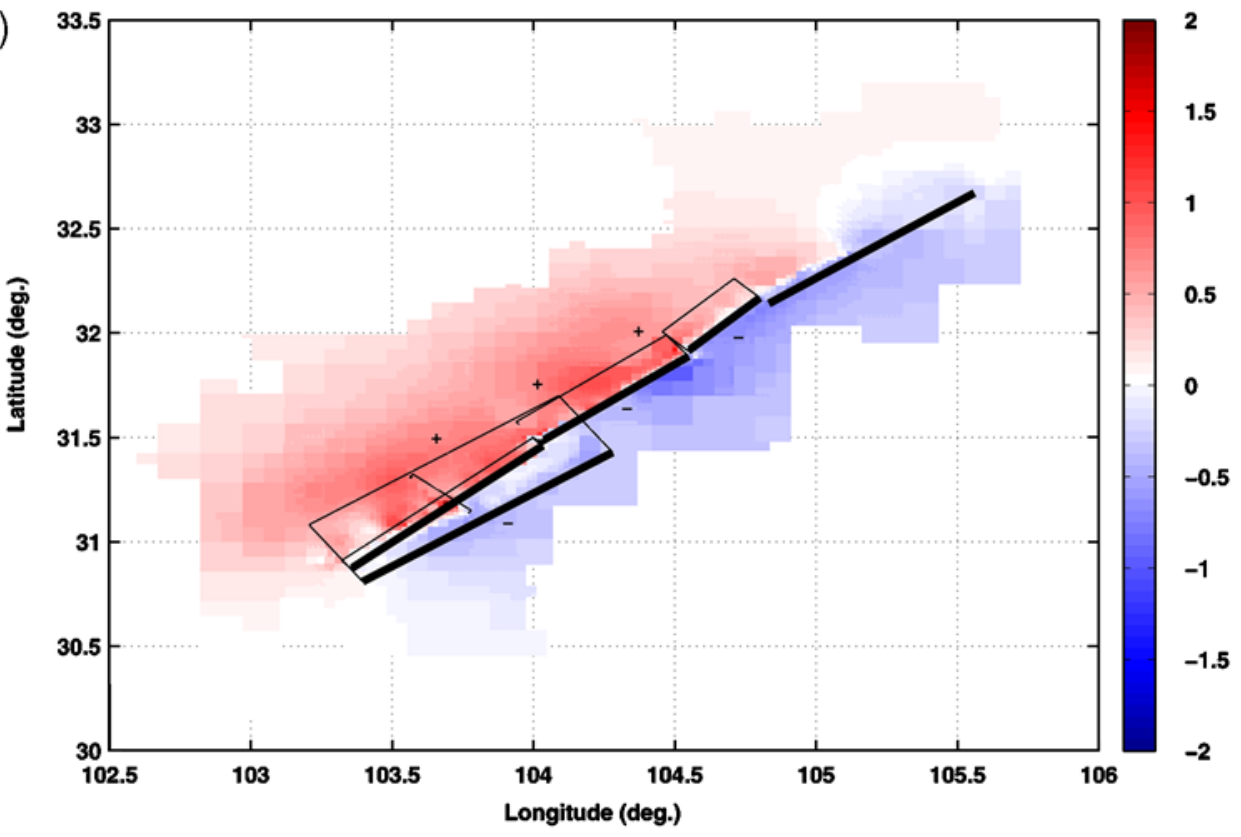

2

1.5

0.5

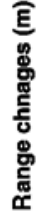

(b)

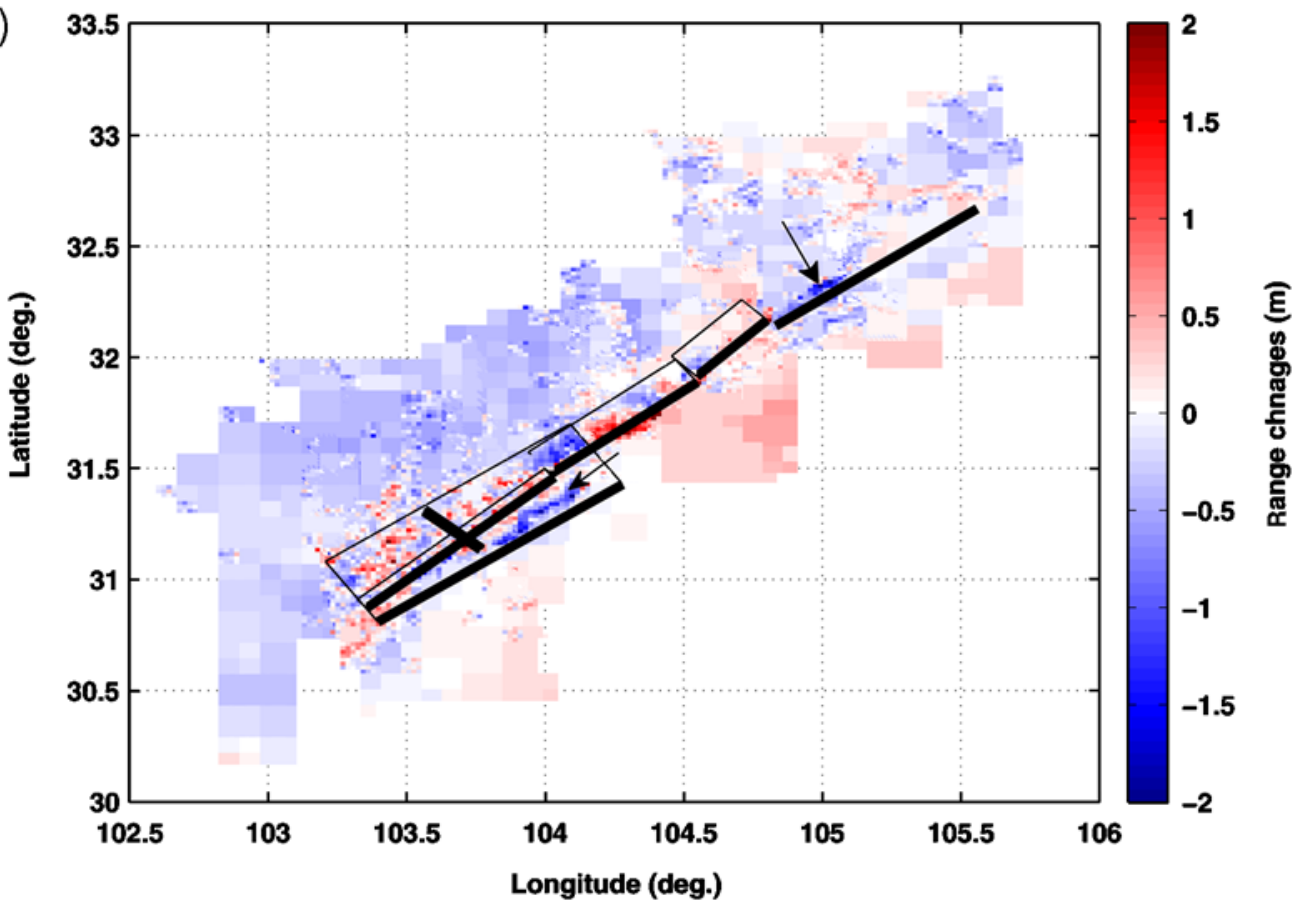

Figure 10. (a) Predicted range offset data based on the source model shown in Figure 4 and Figure 5, (b) Residuals between the observed and predicted range offset data. Plane view of the six fault segments is also shown, and thick lines are the surface traces of the segments. There remain significant localized residuals denoted by one arrow to the $\mathrm{NE}$ and the other to the $\mathrm{SW}$ between the $\mathrm{BF}$ and PF. The color version of this figure is available only in the electronic edition.

near F1 (Fig. 3a), we notice not only sign changes whose locations are consistent with the field observations but also a large negative zone to the south. To consistently explain the small-scale signals as well as the broad signals, the present F1 fault model will need to be replaced by a more complex model, which awaits further studies. The unexplained signals near F5 to the SW (Fig. 10b) are even more puzzling because the location does not exactly coincide with that of the southern discontinuity in the azimuth offset (Fig. 3b); see also figure $3 b$ in Kobayashi et al. (2009). Therefore, the localized negative signals near F5 cannot be explained no matter how we tune the parameters for F5. Considering the absence of the corresponding signals in Figure $3 \mathrm{~b}$ that have no sensitivities to the vertical displacements, the localized signals probably 
(a)

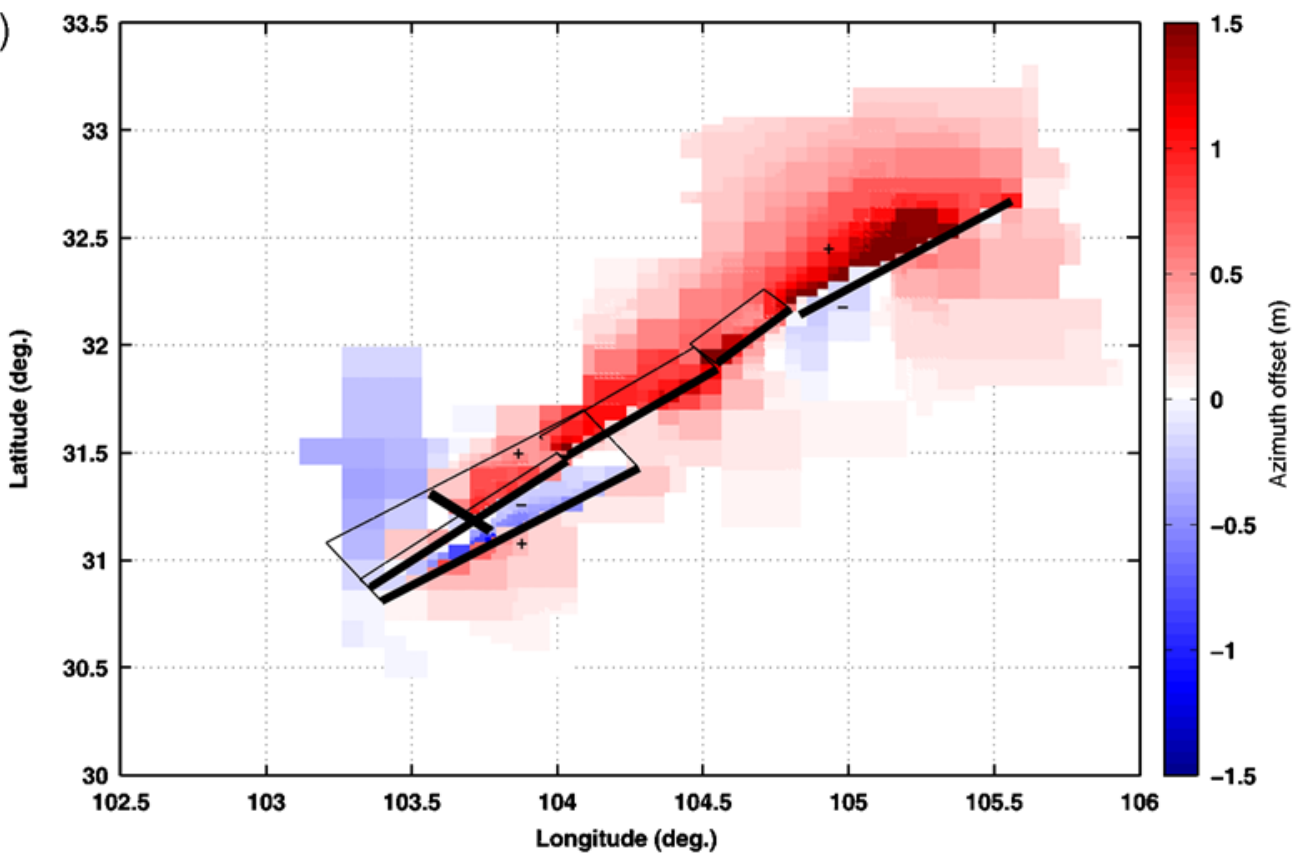

(b)

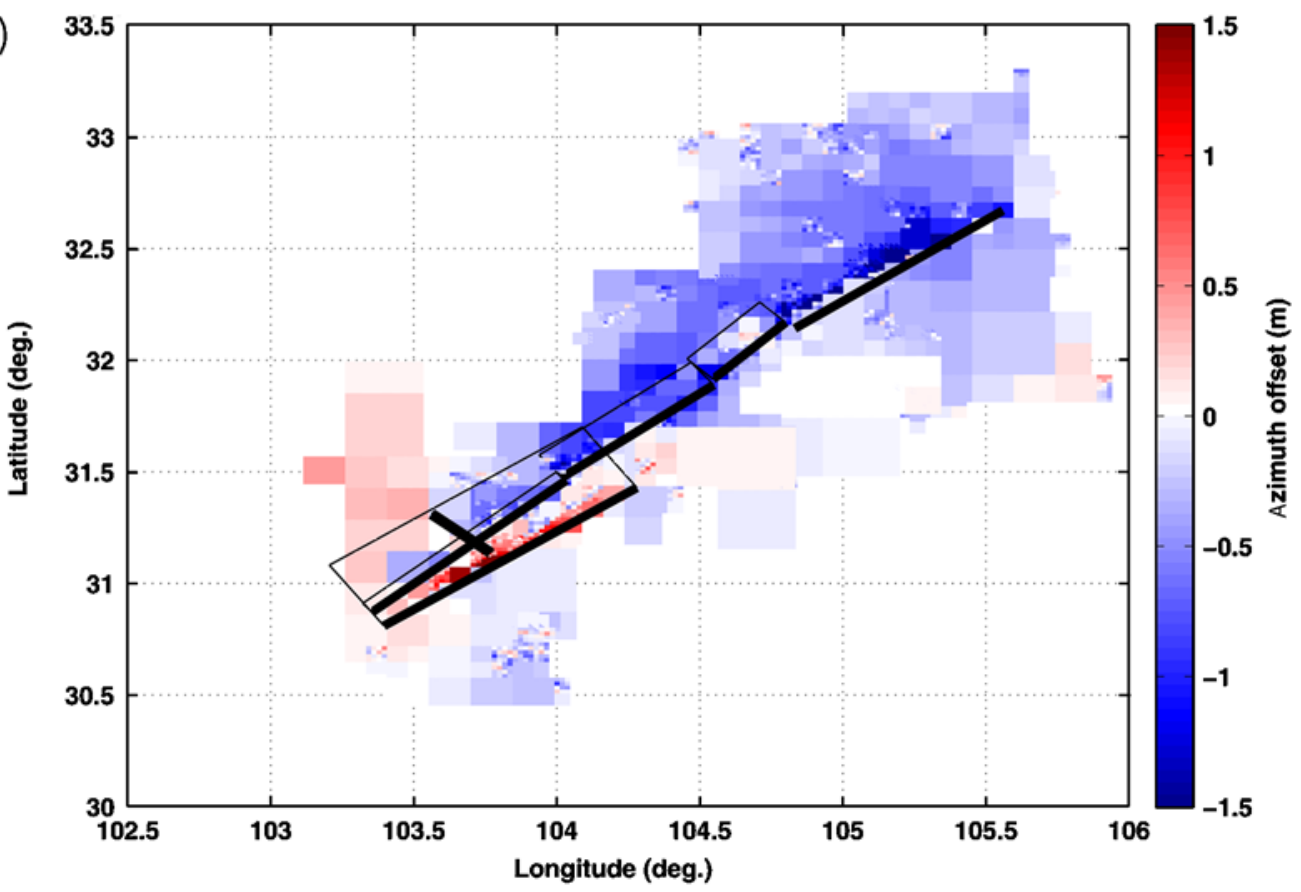

Figure 11. (a) Predicted azimuth-offset data based on the source model shown in Figure 4 and Figure 5, (b) Residuals between the observed and predicted azimuth-offset data. Plane view of the six fault segments is also shown, and thick lines are the surface traces of the segments. The color version of this figure is available only in the electronic edition.

represent uplifting signals, originating in a very shallow depth between the Beichuan and Pengguan faults. In the present framework of elastic dislocation modeling, however, we could not find any plausible fault source that can reproduce the localized signals.

The misfit between the observed and predicted InSAR data in Figure $9 \mathrm{~b}$ is as large as $30 \mathrm{~cm}$ or more except around the fault traces, which we admit is quite large compared to previous fault modeling studies. The large misfits presum- ably occur because we did not apply any corrections for either tropospheric or ionospheric effects. Although it is known that the larger the spatial scale, the more significant the tropospheric effects (e.g., Hanssen, 2001; Furuya et al., 2007), the ionospheric effects seem to have similar spectral characteristics to those of the troposphere. The ionospheric effects on the L-band InSAR and pixel-offset data, however, have not been extensively examined in detail, and further studies are necessary. 


\section{Conclusion}

Using ALOS/PALSAR data, we studied the coseismic crustal deformation associated with the 2008 Wenchuan earthquake. Range and azimuth offset data were crucial to identifying the surface ruptures due to the earthquake and helpful in constructing a fault source model. The earthquake rupture style appears to have changed from the SW to the NE. To the SW, both the Beichuan and Pengguan faults were involved, whose slip consisted initially of thrust slip and subsequently of both thrust and right-lateral slip. The dip angle of the two fault segments to the SW is estimated to be $55^{\circ}$ for the Beichuan fault and $35^{\circ}$ for the Pengguan fault, respectively. We suggest that as the rupture propagated further to the NE, right-lateral slip dominated and that the dip angle of the fault segment became almost vertical.

\section{Data and Resources}

We generated all the interferograms and pixel-offset data from PALSAR level 1.0 data, using the commercial software package from Gamma Remote Sensing. PALSAR level 1.0 data used in this study were provided from the PALSAR Interferometry Consortium to Study our Evolving Land surface (PIXEL) and the Earthquake Working Group under a cooperative research contract with the Japan Aerospace Exploration Agency (JAXA). The ownership of PALSAR data belongs to the Ministry of Economy, Trade and Industry and JAXA. PALSAR level 1.0 data are also available from the Remote Sensing and Technology Center of Japan (http://www. alos-restec.jp, last accessed August 2010). The Global Centroid Moment Tensor Project catalog is available at http:// www.globalcmt.org/ (last accessed August 2010). All figures in this paper were made using Matlab (http://www. mathworks.com, last accessed August 2010).

\section{Acknowledgments}

This study is supported partly by KAKENHI (19340123 and 20900002) and partly by the Ministry of Education, Culture, Sports, Science and Technology (MEXT) of Japan, under its Observation and Research Program for Prediction of Earthquakes and Volcanic Eruptions. Comments from two anonymous reviewers and associate editor Z.-K. Shen significantly improved the manuscript.

\section{References}

Bos, A. G., and W. Spakman (2003). The resolving power of coseismic surface displacement data for fault slip distribution at depth, Geophys. Res. Lett. 30, no. 21, 2110, doi 10.1029/2003GL017946.

Burchfiel, B. C., L. H. Royden, R. D. van der Hilst, B. H. Hager, Z. Chen, R. W. King, C. Li, J. Lü, H. Yao, and E. Kirby (2008). A geological and geophysical context for the Wenchuan earthquake of 12 May 2008, Sichuan, People's Republic of China, GSA Today 26, no. 7, doi 10.1130/GSATG18A.1.

Burchfiel, B. C., C. Zhiliang, L. Yuping, and L. H. Royden (1995). Tectonics of the Longmen Shan and adjacent regions, central China, Int. Geol. Rev. 37, 661-735.
Bürgmann, R., P. A. Rosen, and E. J. Fielding (2000). Synthetic aperture radar interferometry to measure Earth's surface topography and its deformation, Аnпи. Rev. Earth Planet. Sci. 28, 169-209.

Costantini, M. (1998). A novel phase unwrapping method based on network programming, IEEE Trans. Geosci. Remote Sens. 36, no. 3, 813-821.

Densmore, A. L., M. A. Ellis, Y. Li, R. Zhou, G. S. Hancock, and N. Richardson (2007). Active tectonics of the Beichuan and Pengguan faults at the eastern margin of the Tibetan Plateau, Tectonics 26, TC4005, doi 10.1029/2006TC001987.

Fialko, Y. (2004). Probing the mechanical properties of seismically active crust with space geodesy: Study of the coseismic deformation due to the $1992 M_{\mathrm{w}} 7.3$ Landers (southern California) earthquake, J. Geophys. Res. 109, no. B03307, doi 10.1029/2003JB002756.

Fialko, Y., M. Simons, and D. Agnew (2001). The complete (3-D) surface displacement field in the epicentral area of the $1999 M_{\mathrm{w}} 7.1$ Hector Mine earthquake, California, from space geodetic observations, Geophys. Res. Lett. 28, no. 16, 3063-3066.

Furuya, M., and S. P. Satyabala (2008). Slow earthquake in Afghanistan detected by InSAR, Geophys. Res. Lett. 35, L06309, doi 10.1029/ 2007 GL033049.

Furuya, M., K. Mueller, and J. Wahr (2007). Active salt tectonics in the Needles District, Canyonlands (Utah) as detected by interferometric synthetic aperture radar and point target analysis: 1992-2002, J. Geophys. Res. 112, no. B06418, doi 10.1029/2006JB004302.

Gan, W., P. Zhang, Z. K. Shen, Z. Niu, M. Wang, Y. Wan, D. Zhou, and J. Cheng (2007). Present-day crustal motion within the Tibetan Plateau inferred from GPS measurements, J. Geophys. Res. 112, no. B08416, doi 10.1029/2005JB004120.

Gray, A. L., K. E. Mattar, and G. Sofko (2000). Influence of ionospheric electron density fluctuations on satellite radar interferometry, Geophys. Res. Lett. 27, 1451-1454.

Hanssen, R. (2001). Radar Interferometry: Data Interpretation and Error Analysis, Kluwer Academic Publishers, Netherlands, 328 pp.

Hao, K. X., H. Si, H. Fujiwara, and T. Ozawa (2009). Coseismic surfaceruptures and crustal deformations of the 2008 Wenchuan earthquake $M_{\mathrm{w}}$ 7.9, China, Geophys. Res. Lett. 36, L11303, doi 10.1029/ 2009GL037971.

Hikima, K. (2008). The eastern Sichuan earthquake fault model, Earthquake Research Institute, University of Tokyo, Tokyo, Japan, available from http://www.eri.u-tokyo.ac.jp/topics/china2008/source_eng.html (last accessed August 2010).

Huang, Y., J. Wu, T. Zhang, and D. Zhang (2008). Relocation of the $M 8.0$ Wenchuan earthquake and its aftershock sequence, Sci. China D Earth Ser. 51, no. 12, 1703-1711.

Hubbard, J., and J. H. Shaw (2009). Uplift of the Longmen Shan and Tibetan Plateau, and the 2008 Wenchuan $(M=7.9)$ earthquake, Nature 458, 194-197, doi 10.1038/nature07837.

Jarvis, A., H. I. Reuter, A. Nelson, and E. Guevara (2008). Hole-filled seamless SRTM data V4, International Centre for Tropical Agriculture (CIAT), available from http://srtm.csi.cgiar.org (last accessed August 2010).

Ji, C. (2008). Preliminary result of the May 12, $2008 M_{\mathrm{w}}$ 7.97 ShiChuan Earthquake, University of California, Santa Barbara, California, USA, http://www.geol.ucsb.edu/faculty/ji/big_earthquakes/2008/05/ 12/ShiChuan.html (last accessed August 2010).

Jónsson, S., H. Zebker, P. Segall, and F. Amelung (2002). Fault slip distribution of the $1999 M_{\mathrm{w}} 7.1$ Hector Mine, California, earthquake, estimated from satellite radar and GPS measurements, Bull. Seismol. Soc. Am. 92, 1377-1389.

Kobayashi, T., Y. Takada, M. Furuya, and M. Murakami (2009). Locations and types of ruptures involved in the 2008 Sichuan earthquake inferred from SAR image matching, Geophys. Res. Lett. 36, L07302, doi 10.1029/2008GL036907.

Liu-Zeng, J., Z. Zhang, L. Wen, P. Tapponnier, J. Sun, X. Xing, G. Hu, Q. Xu, L. Zeng, L. Ding, C. Ji, K. W. Hudnut, and J. van der Woerd (2009). Co-seismic ruptures of the 12 May 2008, Ms 8.0 Wenchuan earthquake, Sichuan: East-west crustal shortening on oblique, parallel 
thrusts along the eastern edge of Tibet, Earth Planet. Sci. Lett. 286, $355-370$.

Lohman, R. B., and M. Simons (2005). Some thoughts on the use of InSAR data to constrain models of surface deformation: Noise structure and data downsampling, $G^{3}$ 6, Q01007, doi 10.1029/2004GC000841.

Meade, B. J. (2007). Present-day kinematics at the India-Asia collision zone, Geology 35, no. 1, 81-84.

Michel, R., J.-P. Avouac, and J. Taboury (1999). Measuring ground displacements from SAR amplitude images: Application to the Landers earthquake, Geophys. Res. Lett. 26, 875-878.

Motagh, M., J. Klotz, F. Tavakoli, Y. Djamour, S. Arabi, H.-U. Wetzel, and J. Zschau (2006). Combination of precise leveling and InSAR data to constrain source parameters of the $M_{\mathrm{w}}=6.5,26$ December 2003 Bam earthquake, Pure Appl. Geophys. 163, 1-18.

National Earthquake Information Center (2008). Magnitude 7.9-eastern Sichuan, China, U. S. Geol. Surv., Denver, Colo. available from http://earthquake.usgs.gov/eqcenter/eqinthenews/2008/us2008ryan (last accessed August 2010).

Nishimura, N., and Y. Yagi (2008). Rupture process for May 12, 2008 Sichuan earthquake, Univ. of Tsukuba, Japan, available from http:// www.geol.tsukuba.ac.jp/ nisimura/20080512 (last accessed August 2010).

Okada, Y. (1992). Internal deformation due to shear and tensile faults in a half-space, Bull. Seismol. Soc. Am. 82, 1018-1040.

Shen, Z. -K., J. Sun, P. Zhang, Y. Wan, M. Wang, R. Bürgmann, Y. Zeng, W. Gan, H. Liao, and Q. Wang (2009). Slip maxima at fault junctions and rupturing of barriers during the 2008 Wenchuan earthquake, Nature Geosci. 2, 718-724.

Shimada, M., T. Ozawa, Y. Fukushima, M. Furuya, and A. Rosenqvist (2008). Japanese L-band radar improves surface deformation monitoring, Eos Trans. AGU 89, 277-278.

Simons, M., Y. Fialko, and L. Rivera (2002). Coseismic deformation from the $1999 M_{\mathrm{w}} 7.1$ Hector Mine, California, earthquake as inferred from InSAR and GPS observations, Bull. Seismol. Soc. Am. 92, no. 4, 1390-1402, doi 10.1785/0120000933.

Tobita, M., M. Murakami, H. Nakagawa, H. Yarai, S. Fujiwara, and P. A. Rosen (2001). 3-D surface deformation of the 2000 Usu eruption measured by matching of SAR images, Geophys. Res. Lett. 28, 42914294.

Tong, X., D. T. Sandwell, and Y. Fialko (2010). Coseismic slip model of the 2008 Wenchuan earthquake derived from joint inversion of interferometric synthetic aperture radar, GPS and field data, J. Geophys. Res. 115, no. B04314, doi 10.1029/2009JB006625.

Wegmüller, U., C. Werner, T. Strozzi, and A. Wiesmann (2006). Ionospheric electron concentration effects on SAR and INSAR, in Proc. of Internat. Geoscience \& Remote Sensing Symposium 2006, IEEE Press, New York, 3731-3734.

Wright, T. J., Z. Lu, and C. Wicks (2003). Source model for the $M_{\mathrm{w}} 6.7,23$ October 2002, Nenana Mountain earthquake (Alaska) from InSAR, Geophys. Res. Lett. 30, 1974, doi 10.1029/2003GL018014.

Wright, T. J., B. E. Parsons, and Z. Lu (2004). Toward mapping surface deformation in three dimensions using InSAR, Geophys. Res. Lett. 31, L01607, doi 10.1029/2003GL018827.

Xu, X., X. Wen, G. Yu, G. Chen, Y. Klinger, J. Hubbard, and J. H. Shaw (2009). Coseismic reverse- and oblique-slip surface faulting generated by the $2008 M_{\mathrm{w}}$ 7.9 Wenchuan earthquake, China, Geology 27, 515-518.

Zhang, Y., W. P. Feng, L. S. Xu, C. H. Zhou, and Y. T. Chen (2009). Spatio-temporal rupture process of the 2008 great Wenchuan earthquake, Sci. China D Earth Ser. 52, no. 2, 145-154.

Department of Natural History Sciences Graduate School of Science Hokkaido University

Sapporo, Japan

(M.F., Y.T.)

Institute of Seismology and Volcanology Graduate School of Science Hokkaido University

Sapporo, Japan

(T.K., M.M.)

Manuscript received 29 August 2009 